\title{
Structural Stability of the Weeks Island Oil Repository
}

\author{
Dale S. Preece, Brian L. Ehgartner
}

\section{Prepared by \\ Sandia National Laboratories \\ Albuquerque, New Mexico 87185 and Livermore, California 94550 \\ for the United States Department of Energy}

under Contract DE-AC04-94AL85000

Approved for public release; distribution is unlimited.

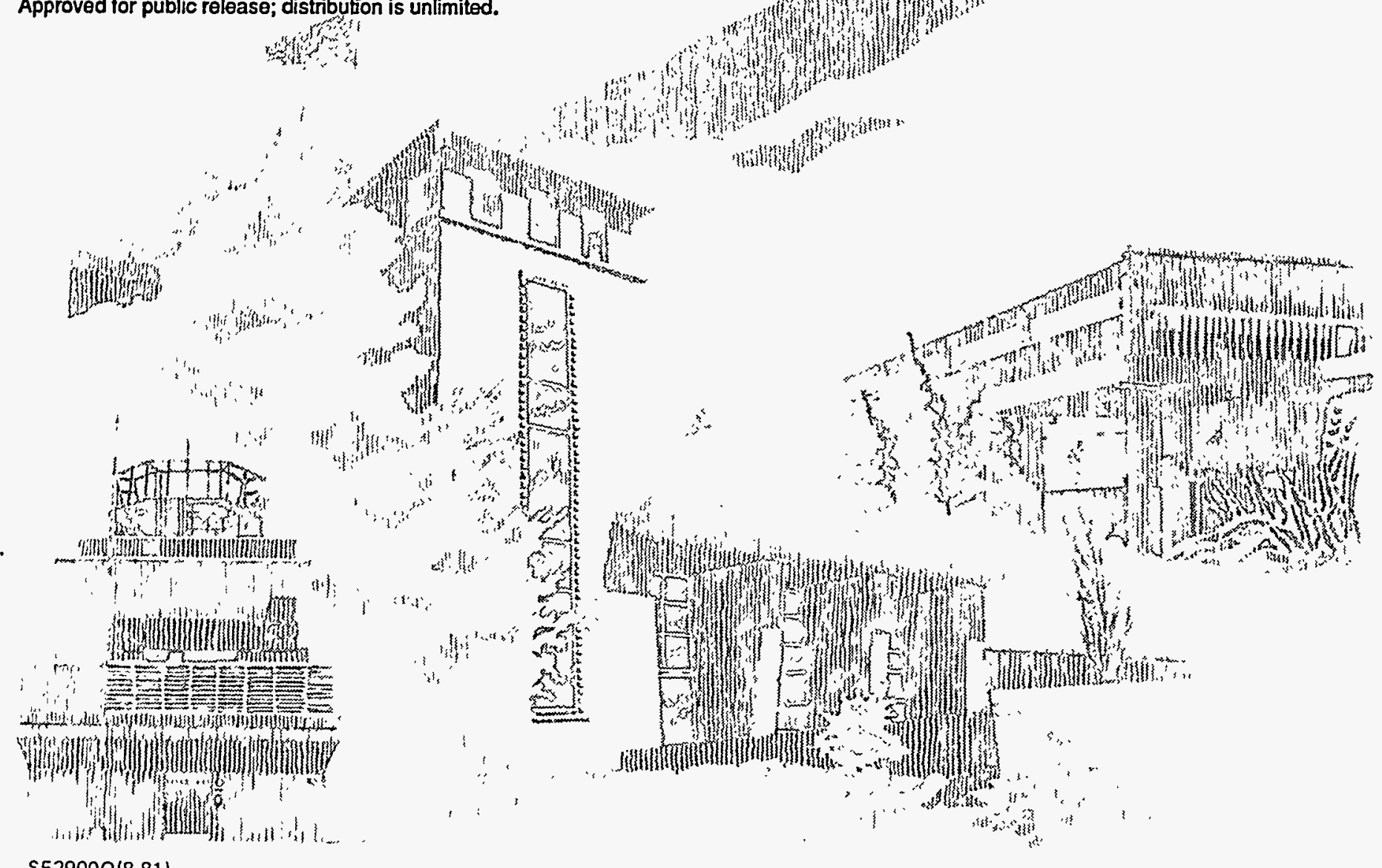


Issued by Sandia National Laboratories, operated for the United States Department of Energy by Sandia Corporation.

NOTICE: This report was prepared as an account of work sponsored by an agency of the United States Government. Neither the United States Government nor any agency thereof, nor any of their employees, nor any of their contractors, subcontractors, or their employees, makes any warranty, express or implied, or assumes any legal liability or responsibility for the accuracy, completeness, or usefulness of any information, apparatus, product, or process disclosed, or represents that its use would not infringe privately owned rights. Reference herein to any specific commercial product, process, or service by trade name, trademark, manufacturer, or otherwise, does not necessarily constitute or imply its endorsement, recommendation, or favoring by the United States Government, any agency thereof or any of their contractors or subcontractors. The views and opinions expressed herein do not necessarily state or reflect those of the United States Government, any agency thereof or any of their contractors.

Printed in the United States of America. This report has been reproduced directly from the best available copy.

Available to DOE and DOE contractors from

Office of Scientific and Technical Information

PO Box 62

Oak Ridge, TN 37831

Prices available from (615) 576-8401, FTS 626-8401

Available to the public from

National Technical Information Service

US Department of Commerce

5285 Port Royal Rd

Springfield, VA 22161

NTIS price codes

Printed copy: A03

Microfiche copy: A01 


\section{DISCLAIMER}

Portions of this document may be illegible in electronic image products. Images are produced from the best available original document. 
SAND94-1026

Distribution

Unlimited Release

Category UC-126

Printed June 1994

\title{
Structural Stability of the Weeks Island Oil Repository
}

\author{
Dale S. Preece \\ Geomechanics Department \\ Brian L. Ehgartner \\ Underground Storage Technology Department \\ Sandia National Laboratories \\ Albuquerque, NM 87185
}

\begin{abstract}
A 3-D finite element analysis was performed to evaluate the stability of the SPR upper and lower oil storage levels at Weeks Island. The mechanical analysis predicted stresses and strains from which pillar stability was inferred using a fracture criterion developed from previous testing of Weeks Island salt. This analysis simulated the sequential mining of the two levels and subsequent oil fill of the mine. The predicted subsidence rates compare well to those measured over the past few years. Predicted failure mechanisms agree with observations made at the time the mine was being modified for oil storage. The modeling technique employed here treats an infinite array of pillars and is a reasonable representation of the behavior at the center of the mine. This analysis predicts that the lower level pillars, at the center of the mine, have fractured and their stability at this time is questionable. Localized pillar fracturing is predicted and implies that the mine is entering a phase of continual time dependent deterioration. Continued and expanded monitoring of the facility and development of methods to assess and predict its behavior are more important now than ever.
\end{abstract}

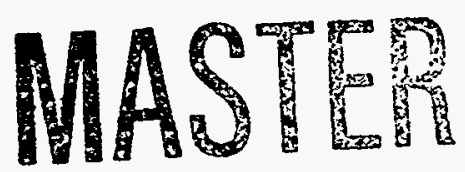




\section{Table of Contents}

Abstract

Table of Contents

i

List of Figures

List of Tables

1.0: Introduction

2.0: Finite Element Model

3.0: Computational Results

3.1: Closure and Subsidence 8

3.2: Von Mises Stress

3.3: Maximum Principle Stress State

13

3.4: Creep Strain Induced Salt Fracture

4.0: Conclusions

References 


\section{List of Figures}

1: Schematic Drawing of the Two SPR Levels at Weeks Island.

2: 3-D Finite Element Model of Weeks Island Mine. 6

3: Calculated Horizontal and Vertical Closure of Upper and Lower Levels 9

4: Calculated Subsidence at the top of the 3-D Finite Element Model 9

5: Calculated Subsidence Rate at the top of the 3-D Finite Element Model 10

6: Von Mises Stress $(\mathrm{Pa})$ in model in 1929.

7: Von Mises Stress $(\mathrm{Pa})$ in model in 1967.

8: Von Mises Stress $(\mathrm{Pa})$ in model in 1980.

9: Von Mises Stress $(\mathrm{Pa})$ in model in 2030.

10: Idealized Spatial Orientation of Maximum Principal Stress Illustrated With Dark Bars. Likely Crack/Fracture Patterns Illustrated Normal to Maximum Principal Stress.

11: Distribution of Maximum Principle Stress $(\mathrm{Pa})$ in 2030.

12: Vertical Pillar Cracks Likely Caused by Tensile Stresses (Intersection C13 of Upper Level - Northeast Corner

13: Salt Detaches at Pillar Corners Where Tensile Cracks Intersect (Intersection F14 of Upper Level.

14: Mean Pressure Versus Ultimate Axial Strain For Weeks Island Salt. Dashed Line is Equation 2.

15: Pillar Decay by Exfoliation in Rooms. Intersection J8 of Upper Level Southwest Corner.

16: Pillar Decay by Exfoliation in Rooms. Intersection 19 of Upper Level.

17: Pillar Decay by Exfoliation in Rooms. Intersection K10 of Upper Level Southeast Corner.

18: Pillar Decay by Exfoliation at Corners. Intersection K7 of Upper Level Southwest Corner.

19: Pillar Decay by Exfoliation at Corners. Intersection I10 of Upper Level.

20: Pillar Decay by Slabbing in Rooms. Intersection G8 of Upper Level.

21: Pillar Decay by Slabbing in Rooms. Room J Between Crosscuts 12 and 13 of Upper Level.

22: Pillar Decay by Slabbing in Rooms. Room H Near Crosscuts 10 of Upper Level.

23: Pillar Decay by Slabbing in Rooms. Intersection H4 of Upper Level Northeast Corner.

24: Pillar Decay by Slabbing at Corners. Intersection H9 of Upper Level.

25: Pillar Decay by Slabbing at Corners. Intersection J9 of Upper Level Southwest Corner.

26: Piles of Ravelled Salt from Exfoliated Pillars. Room A Between Crosscuts 5 and 6 of Upper Level.

27: Piles of Ravelled Salt from Exfoliated Pillars. Intersection F8 of Upper Level Northwest Corner.

28: Piles of Ravelled Salt from Exfoliated Pillars. Intersection E7 of Upper Level. 
29: Detached Pieces of Salt from Slabbed Pillars. Intersection F4 Southeast Corner of Upper Level.

30: Detached Pieces of Salt from Slabbed Pillars. Intersection D14 of Lower Level Southwest Corner.

31: Calculated Spatial Distribution of Fracture Function, Year $=1977$.

Dark Area Indicates Extensive Fracturing.

32: Calculated Spatial Distribution of Fracture Function, Year $=1993$.

Dark Area Indicates Extensive Fracturing.

33: Calculated Spatial Distribution of Fracture Function. Year $=2000$.

Dark Area Indicates Extensive Fracturing.

34: Calculated Spatial Distribution of Fracture Function. Year $=2030$.

Dark Area Indicates Extensive Fracturing.

\section{List of Tables}

1: Model History

7

2: Material Properties

8

3: Weeks Island Quasi-Static Compression Tests 


\subsection{Introduction}

The Weeks Island oil storage facility consists of a two-level room and pillar salt mine that was purchased by DOE from Morton Salt in 1975 and modified for crude oil storage as part of the Strategic Petroleum Reserve. Oil fill of the mine began in 1979 and continued into 1980. It now contains approximately 72 million barrels of oil. The two oil storage levels of the mine are shown schematically in Figure 1.

After sale of the oil storage facility in 1975 and prior to oil fill, Morton Salt opened and operated the Markel Mine which is adjacent to but separated from the DOE facility. The Markel Mine used the same shafts as the DOE facility giving Morton a mine to operate while sinking two new shafts that would provide access to other parts of the Weeks Island Salt Dome.

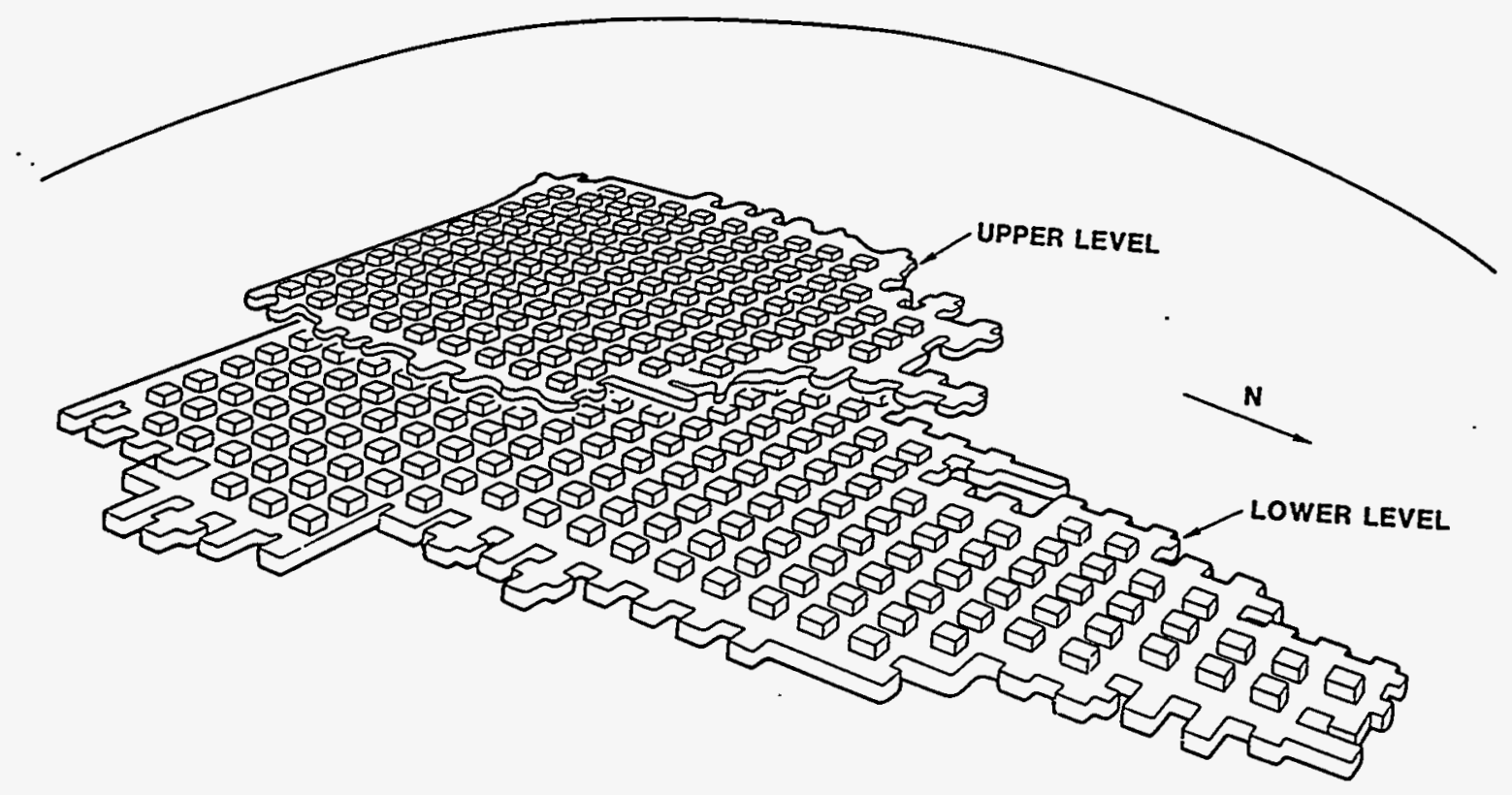

Figure 1. Schematic Drawing of the Two SPR Levels at Weeks Island.

Recent inspections of the Markel Mine have indicated that many of the pillars may be disintegrating and that the mine is entering a stage of progressive deterioration. While instability of the Markel Mine has consequences in itself, it also raises the question of the current condition of the DOE oil storage facility which is also a room and pillar mine similar to the Markel but even older. Since oil fill makes it impossible to directly assess the current condition of the pillars in the oil storage facility, computer simulations have come to the forefront. This report documents a relatively detailed finite element creep simulation 
of the Weeks Island Mine that includes the important historical events and provides an assessment of the current and future stability of the Weeks Island SPR storage facility.

\subsection{Finite Element Model}

The finite element model includes the discretization of the geometry using 3-D finite elements, the material properties of the salt, and the history of the mine which determines the loading of the model. The 3-D geometrical portion of the finite element model used in this simulation is shown in Figure 2.

The model treats pillars on the two levels of the mine and assumes that the upper-level pillars are directly above the lower level pillars. This is a valid assumption based on

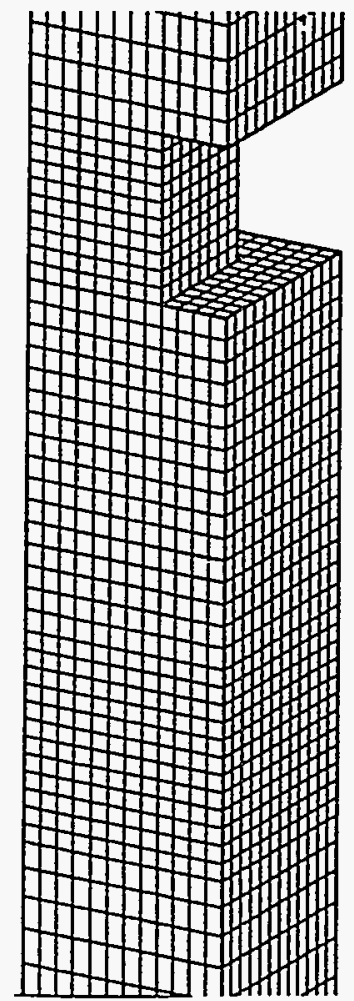

Lower Level Closed

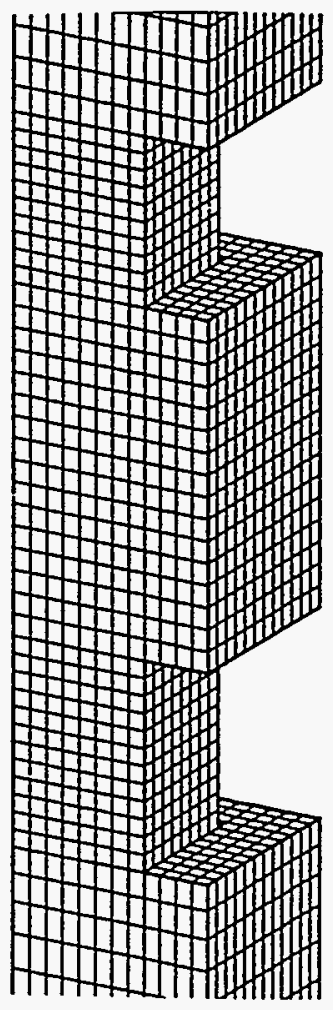

Lower Level Opened

Figure 2. 3-D Finite Element Model of Weeks Island Mine.

examination of the mine survey data [1]. The model incorporates symmetry planes along each side that allow motion parallel to the side of the model but not perpendicular to it. This enables a $1 / 4$ pillar model to treat the entire pillar. The use of symmetry planes in this manner also forces the model to simulate an infinite array of pillars. This is appropriate for modeling the pillars in the geographical center of the mine. Pillars around the perimeter of the mine will experience a different loading than those in the central portion of the mine. The loading will be complicated by the ability of the roof to deform (and hence load the 
pillars) and by stress concentrations generated by the edge of the mine. In general the 1977 inspection of the upper and lower levels [1] showed the pillars in the central portions of the mine to be degraded more than those along the perimeter. The top of the model is approximately the interface between the overburden and the salt at the geographical center of the mine. The pressure on top of the model corresponds to the weight of the overburden at that level. Since salt creep rate is temperature dependent, a temperature gradient was assumed for the model. The temperature gradient used was $0.0122^{\circ} \mathrm{F} / \mathrm{ft}$ and the surface temperature was assumed to be $80.6^{\circ} \mathrm{F}[2][3]$.

The model is designed to approximate the history of the mine. This is accomplished by beginning the calculation with the upper level open and the lower level unexcavated. The lower level is excavated during the calculation through element deletion of the material filling the room around the lower pillar. Oil fill is simulated by applied pressure to the roof, floors and walls of each pillar. The fluid pressure is dependent on unit weight and depth of the fluid below the free surface. In this case the unit weight of oil was assumed to be 57.4 $\mathrm{lb} / \mathrm{ft}^{3}\left(919.5 \mathrm{Kg} / \mathrm{m}^{3}\right)$ and the free surface is assumed to be at $-470 \mathrm{ft}$ msl (mean sea level) $(-143.256 \mathrm{~m})$. The history of the model is given in Table 1 below.

The excavation years were chosen as the average mining date for the upper and lower levels. These excavation years result in model predicted salt slabbing in the upper and lower layers that compare well with what was observed in the mine surveys done in 1977 [1].

\section{Table 1: Model History}

Year $\underline{\text { Event }}$

1929 Excavate Upper Level

1967 Excavate Lower Level

$1980 \quad$ Oil Fill

2030 Terminate Simulation

The secondary creep model is implemented in the finite element program JAC 3-D [10] by expressing the creep strain rate magnitude, $\dot{\bar{\varepsilon}}$, as a function of effective stress $\bar{\sigma}$.

$$
\dot{\bar{\varepsilon}}=D e^{\frac{-Q}{R T}} \bar{\sigma}^{n}
$$

Where $D$, and $n$ are constants for a specific salt, $Q$ is the thermal activation energy for a specific salt, $R$ is the universal gas constant $\left(1.987 \mathrm{Kcal} /\left(\right.\right.$ mole $\left.\left.^{\circ} \mathrm{K}\right)\right)$ and $T$ is the material 
temperature. The creep constants satisfying equation 1 as well as the elastic material properties for the salt are given in Table 2 below

Table 2: Materlal Properties

Parameter

$D$

$n$

$Q / R$

E/12.5

$\vartheta$

$\Upsilon$
Name

Creep Constant

Stress Exponent

Thermal Constant

Reduced Young's Modulus

Poisson's Ratio

Density $\underline{\text { Value }}$

$5.79 \mathrm{E}-36 \frac{1}{(s)(P a)^{n}}$

4.9

$6039 / \mathrm{K}$

2.47E9 $\mathrm{Pa}$

0.3

$2300 \mathrm{Kg} / \mathrm{m}^{3}$

Weeks Island salt has not been tested for creep response so the creep model parameters are from West Hackberry salt. These parameters have been used previously in other studies of Weeks Island with good agreement between field data and predictions[2][3]. Elastic and strength properties were measured on Weeks Island salt [4] so the elastic material properties given in Table 2 are specific to Weeks Island. Even though the material properties are specific to Weeks Island the modulus used in the calculations is the original modulus divided by 12.5 . The practice of dividing the modulus by 12.5 is necessary with this simple creep formulation in order to compute the correct closure rates. This practice is documented in references [2],[3] and [7].

\subsection{Computational Results}

\subsection{Closure and Subsidence}

The calculated vertical closure (floor to ceiling in the center of the room) and horizontal closure (at pillar mid-height) are presented in Figure 3. The closures and closure rates are comparable to those obtained from a previous study [3] which also had favorable comparison to Morton closure data taken in $25 \mathrm{ft}$ high rooms on the lower level. The larger closure rate of the lower level is due to the increased depth and greater stress. Oil fill starting in 1979 causes a slight reduction in closure rates (knee in curve) due to the fluid pressure on the pillar walls and the subsequent reduction in the pillar stresses that drive creep. This behavior is more evident in the lower level where the stresses are higher. The subsidence or vertical movement of the top of the model is given in Figure 4. This curve 


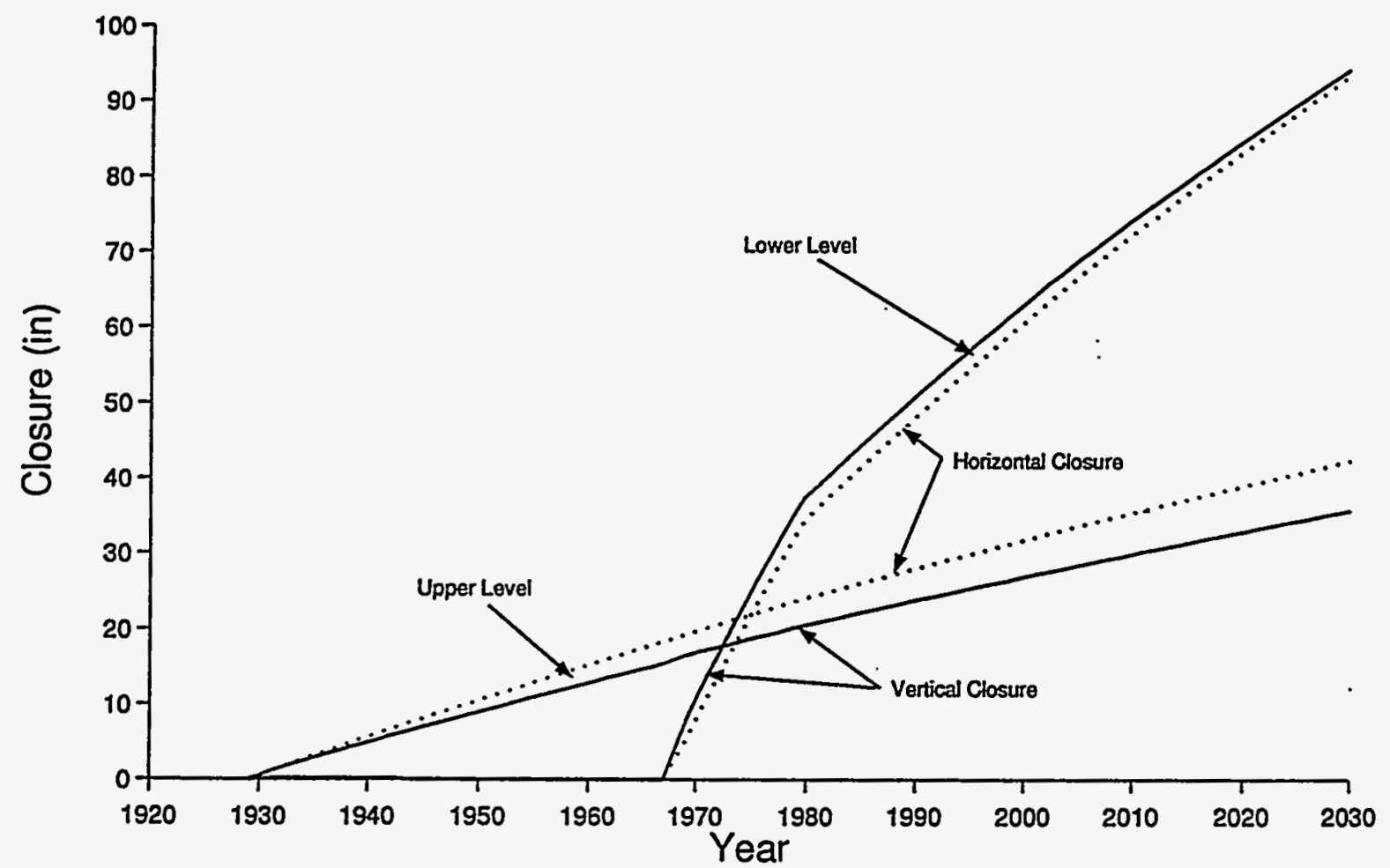

Figure 3. Calculated Horizontal and Vertical Closure of Upper and Lower Levels

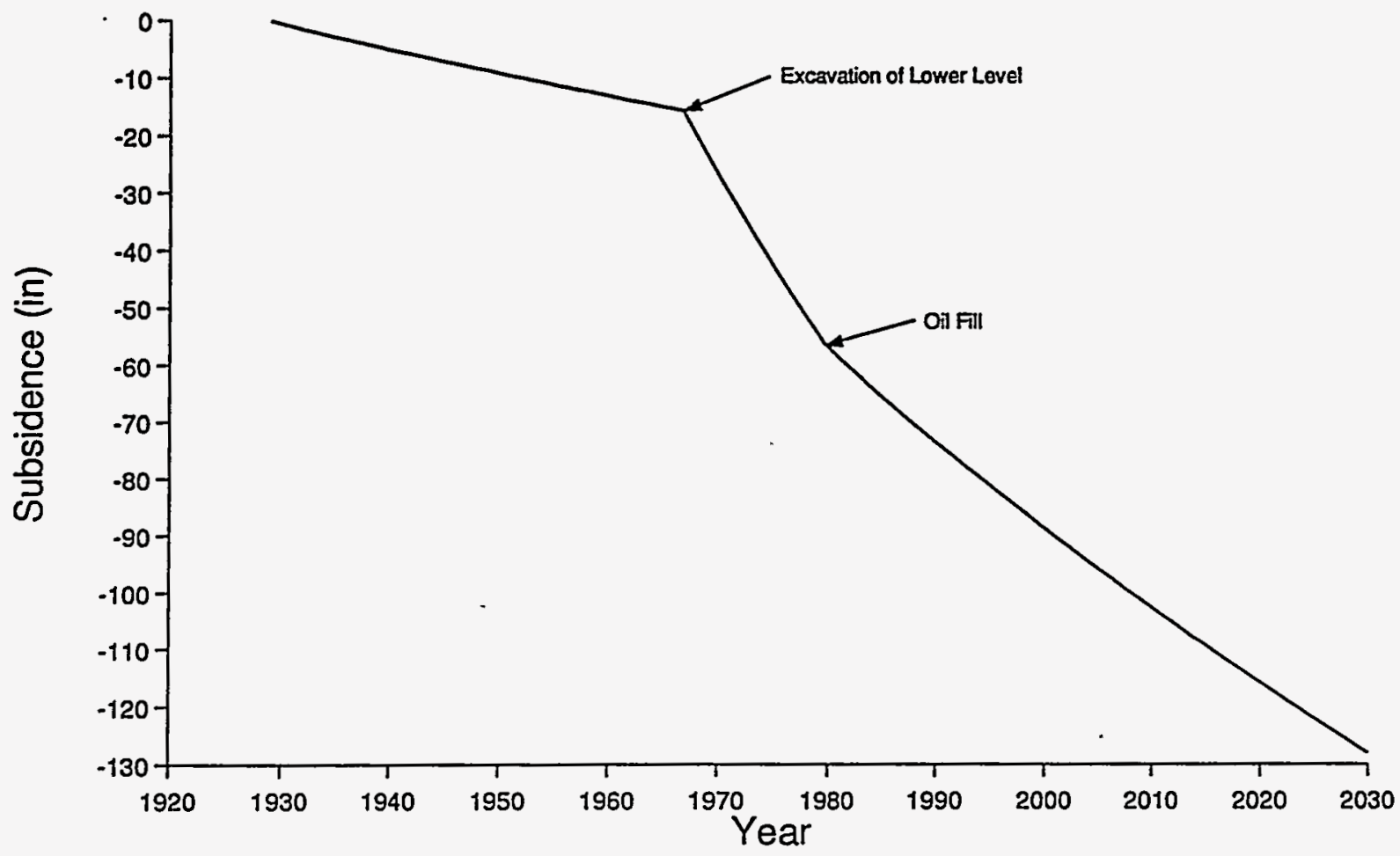

Figure 4. Calculated Subsidence at the top of the 3-D Finite Element Model 


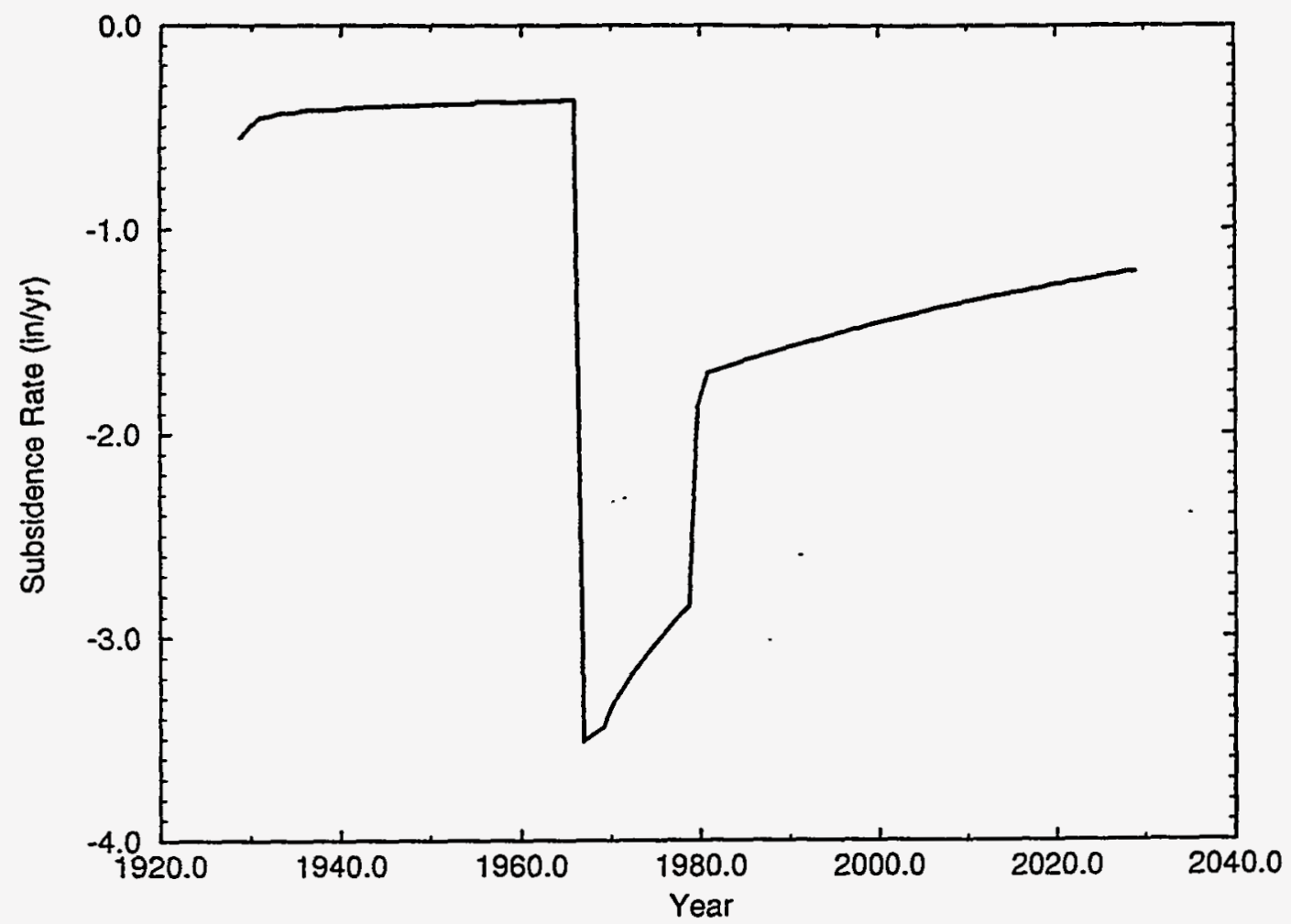

Figure 5. Calculated Subsidence Rate at the top of the 3-D Finite Element Model

reflects the history associated with the simulation where new excavations and oil fill have an impact on the model behavior. Differentiation of the curve in Figure 4 using forward difference gives the subsidence rate curve in Figure 5. The subsidence rate in the year 1990 is approximately $1.64 \mathrm{in} / \mathrm{yr}$. This compares quite well with the average subsidence measured over the mine. Field subsidence survey data [5] that shows subsidence rates of $2.4 \mathrm{in} / \mathrm{yr}$ over the geographical center of the mine and $0.60 \mathrm{in} / \mathrm{yr}$ at the edge of the mine. It is important to point out that the subsidence data from the simulation is actually at the interface between the salt and the overburden ( $-160 \mathrm{ft}$.) though the difference in subsidence between this location and the surface is probably negligible. The good comparison between observed and predicted subsidence rates gives the model some credibility.

\subsection{Von Mises Stress}

Von Mises stress is used to evaluate the mechanisms driving creep. It is derived from the complete stress tensor and is a scalar representation of the shear stresses at a point within the material. It is the shear stresses that mobilize salt creep through dislocation glide within each salt crystal. Figures 6 through 9 show the distribution of von Mises stress on the Weeks Island model in the years 1929, 1967, 1980 and 2030.

The influence of von Mises stress on the closure and subsidence rates is evident from the plots. Activities that increase von Mises stress, such as excavation, also increase the closure and subsidence rates. Oil fill reduces the von Mises stress and thus reduces the rates of closure and subsidence. 


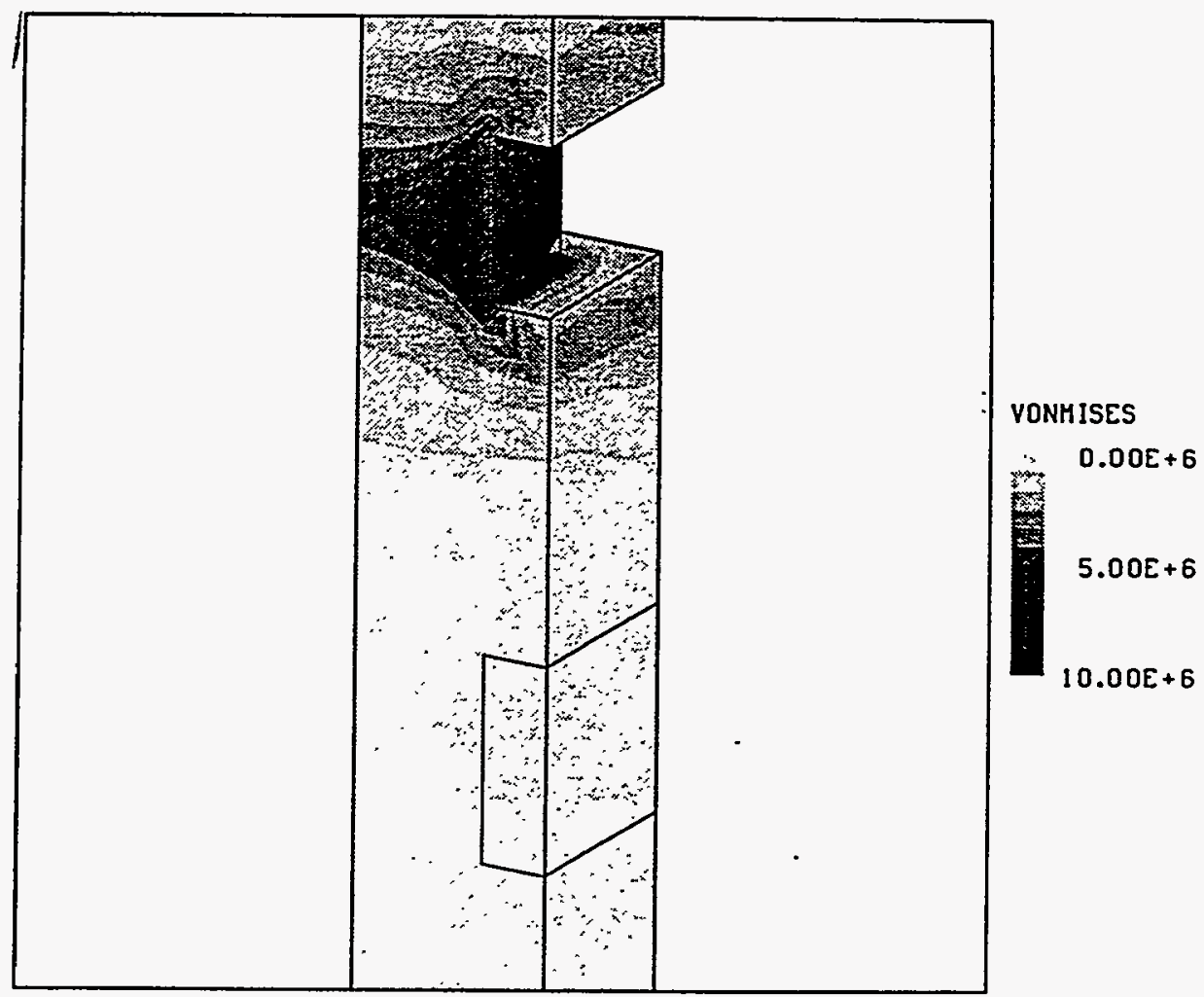

Figure 6. Von Mises Stress $(\mathrm{Pa})$ in model in 1929.

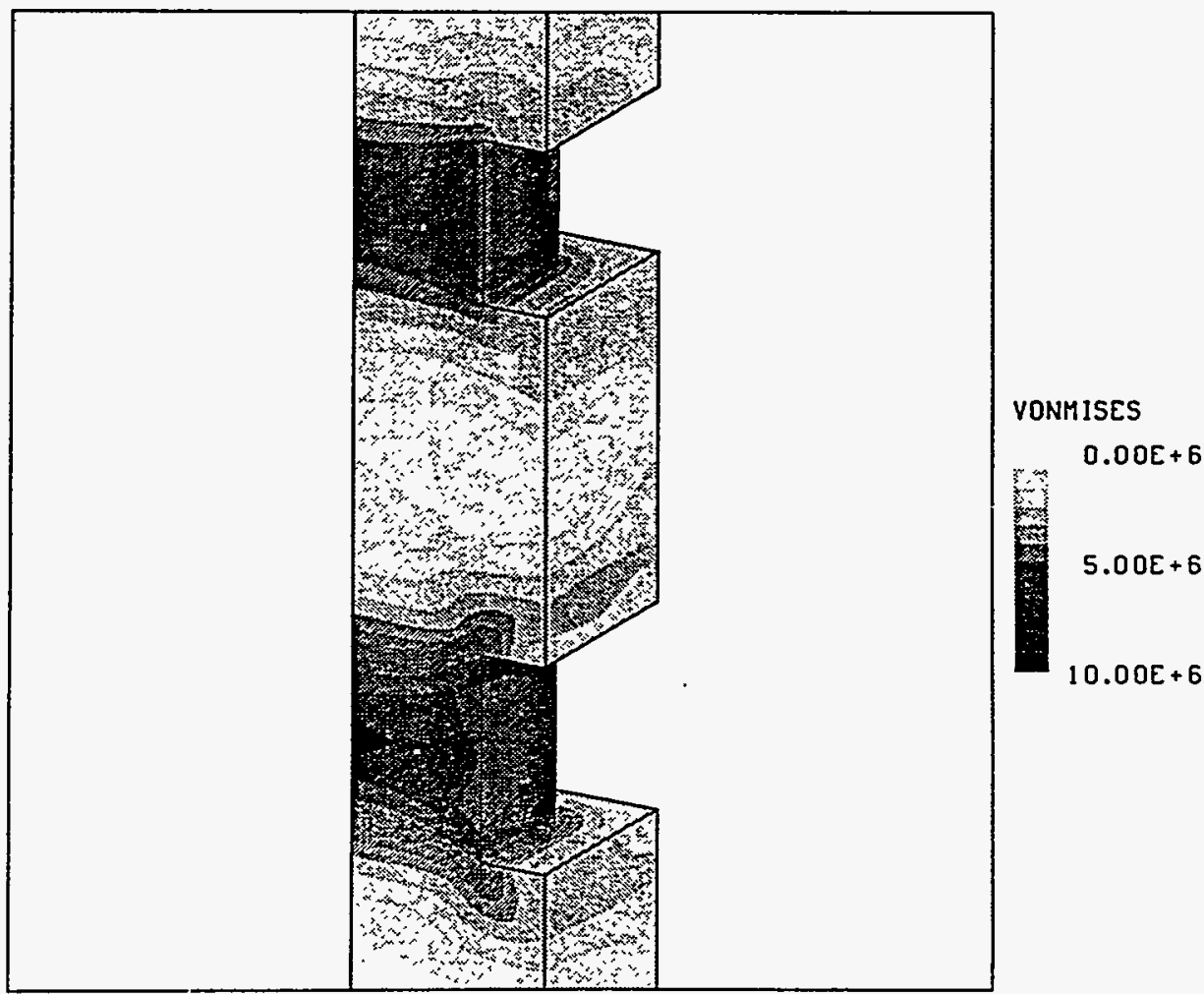

Figure 7. Von Mises Stress $(\mathrm{Pa})$ in model in 1967. 


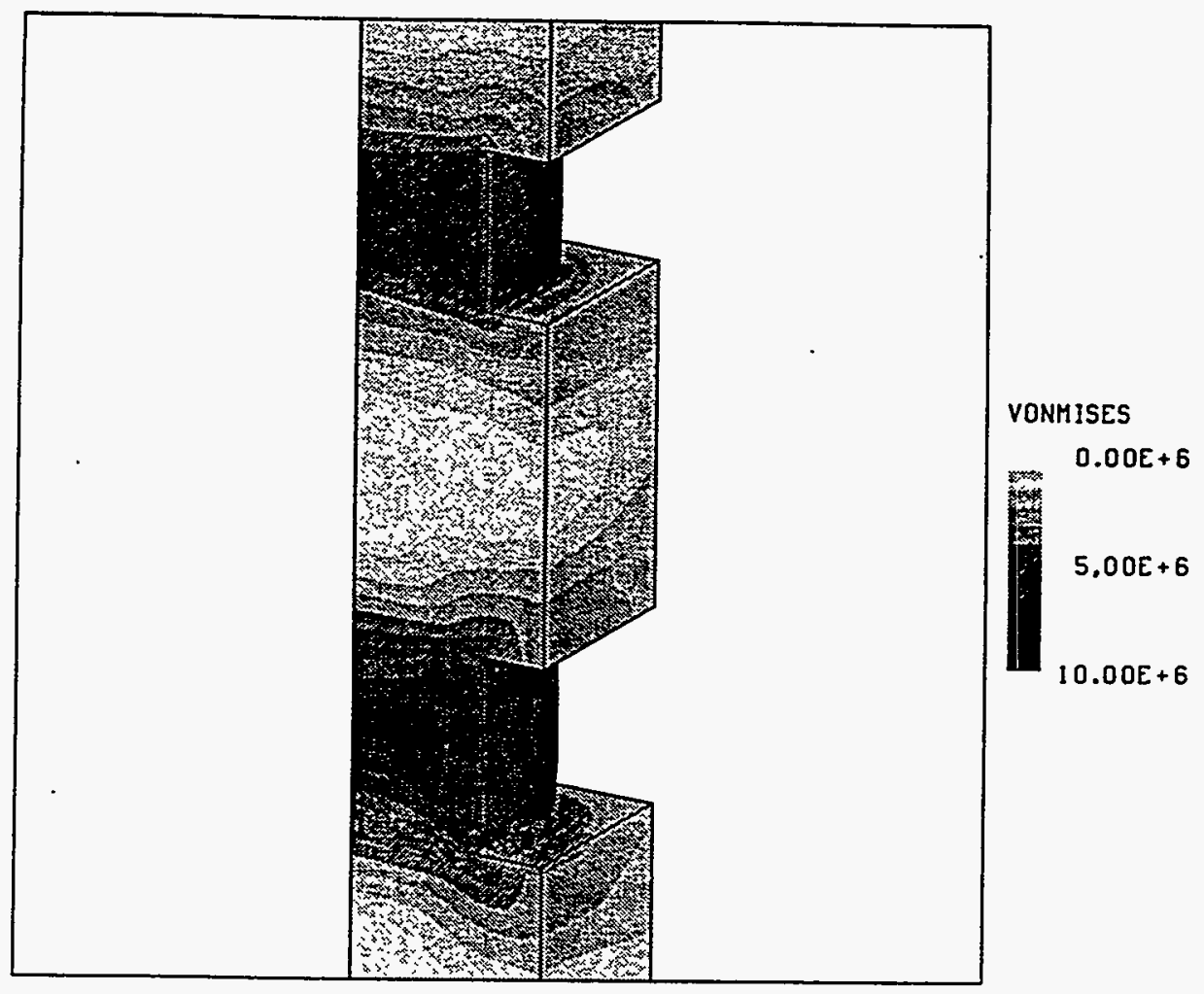

Figure 8. Von Mises Stress $(\mathrm{Pa})$ in model in 1980.

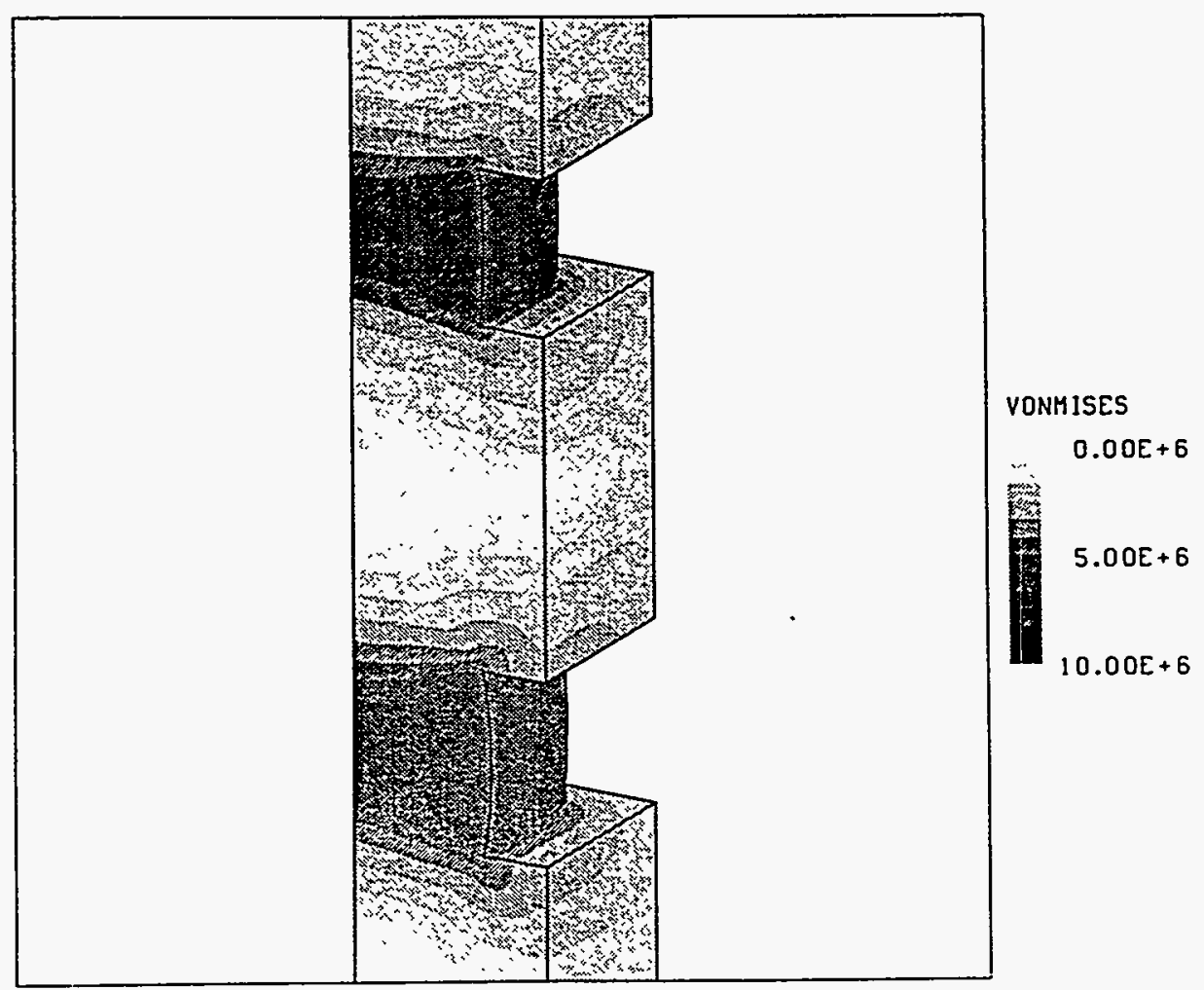

Figure 9. Von Mises Stress $(\mathrm{Pa})$ in model in 2030. 


\subsection{Maximum Principal Stress State}

A principal stress tensor has three orthogonal components which can vary from point to point within the rock mass in both orientation and magnitude. In this report negative stresses represent compression and positive stresses indicate tension. Thus, the maximum principal stress is the component that is the most tensile of the three components in the tensor, or in the absence of tension, the least compressive.

It is important to examine the maximum principal stress state in the pillars, roof and floor of the mine because the magnitude and orientation of these stresses control the formation of cracks and fractures in the salt. Cracks/fractures may be caused by tensile failure or by accumulation of creep strain in compression.

The spatial orientation of the maximum principal stresses predicted by this model are shown in Figure 10. It should be noted that small localized variations to this pattern will occur, especially at the corners where the pillar intersects the roof and floor. This spatial orientation of maximum principal stress is a product of the geometry of the room and pillar mine. The orientation bars in Figure 10 are generally aligned with directions of material movement into the openings created by mining. This is also the direction along which the material is unloading. Orientation bars on the face of the pillar must be parallel to the

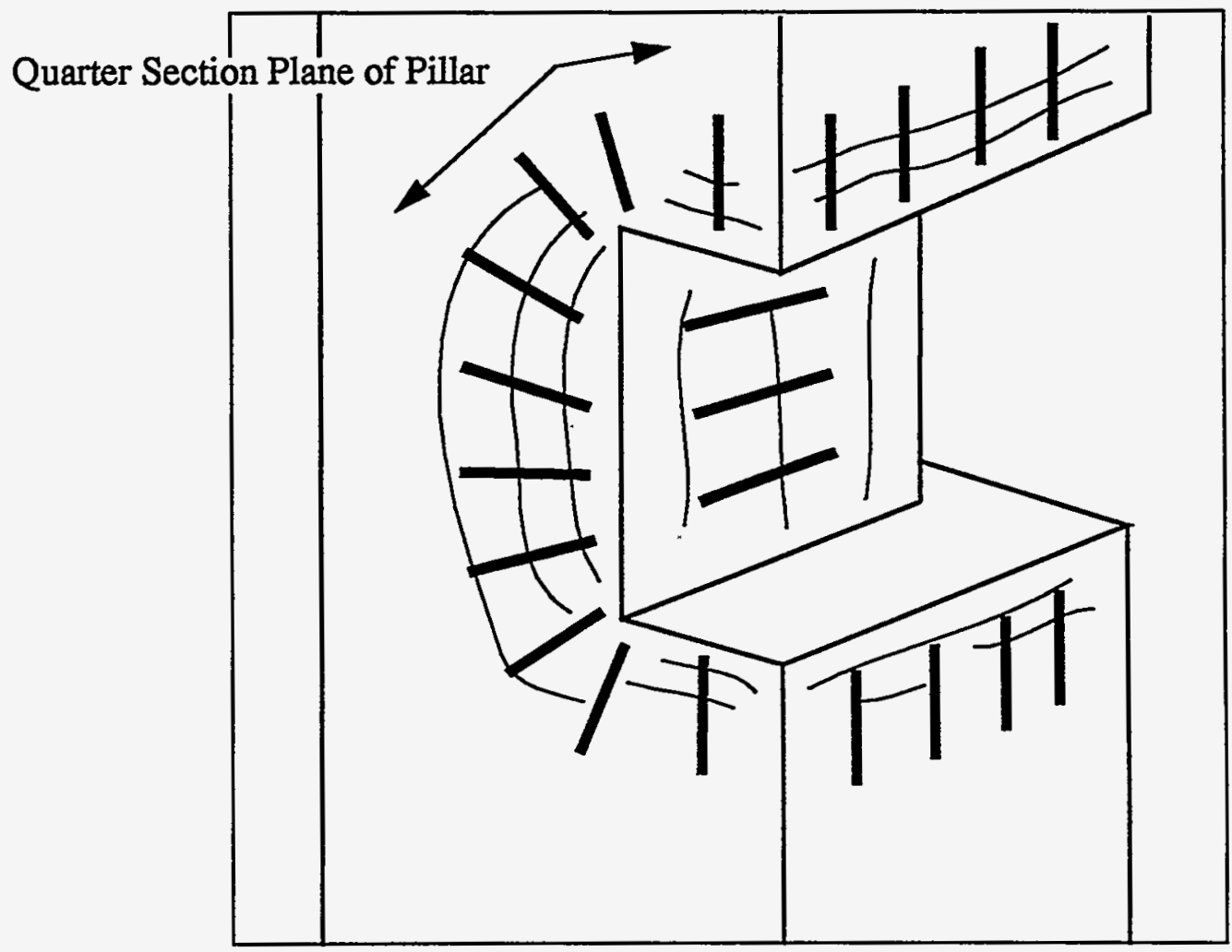

Figure 10. Idealized Spatial Orientation of Maximum Principal Stress Illustrated With Dark Bars. Likely Crack/ Fracture Patterns Illustrated Normal to Maximum Principal Stress. 
face since it is a free surface and no loading can be sustained perpendicular to it.

Cracking and fracture of the salt resulting from tension or creep strain accumulation will be oriented normal to the direction of the maximum principal stress. Figure 10 also illustrates the predicted orientation of the crack/fracture system based on maximum principal stress orientation.

Figure 11 shows the distribution of tensile portion of the maximum principal stress on the model in the year 2030. Since the maximum principal stress in this model remains almost constant with time, the spatial distribution is essentially the same as in the year 1929.

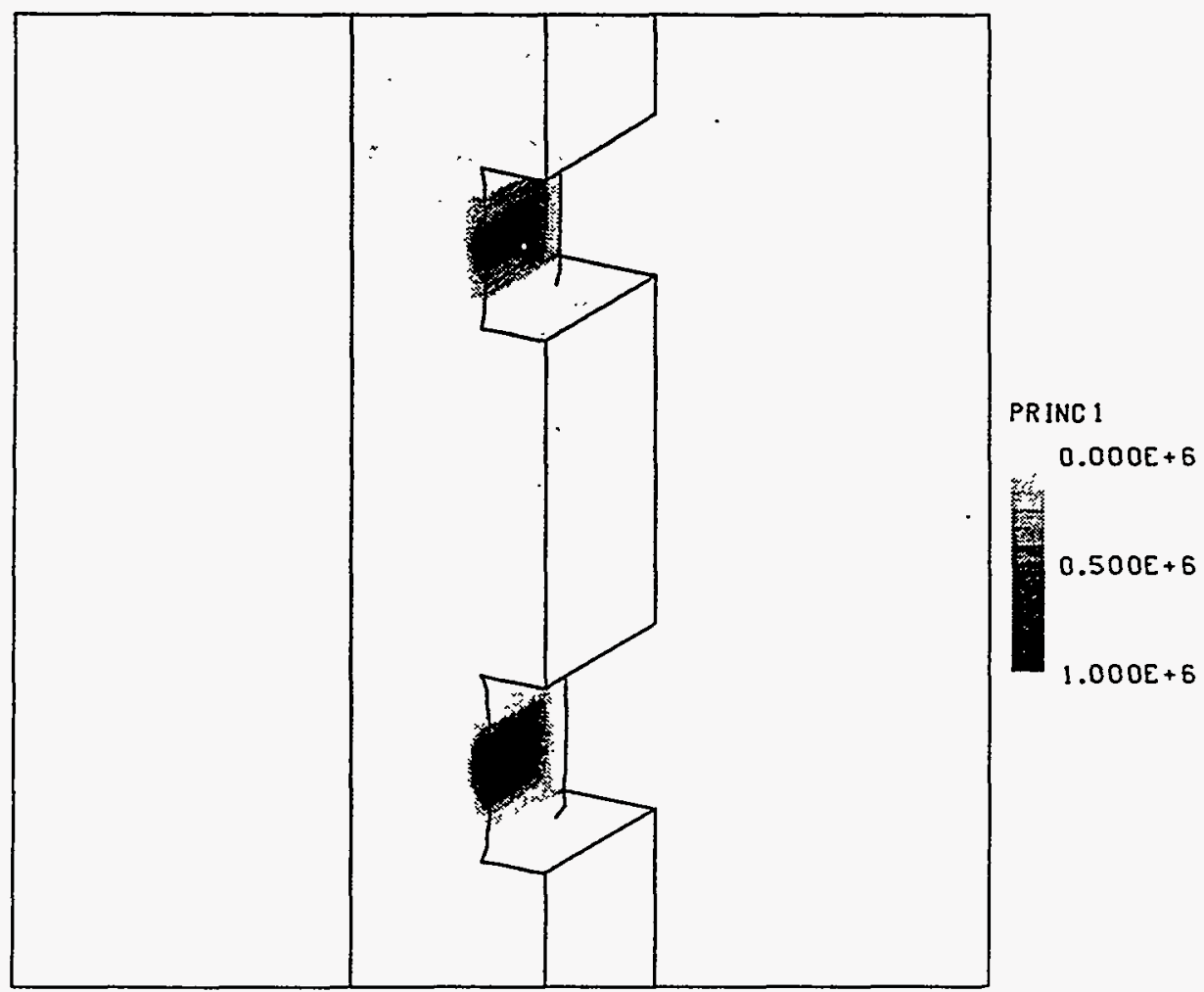

Figure 11. Distribution of Maximum Principal Stress $(\mathrm{Pa})$ in 2030

Cracks that develop in the tensile region indicated in Figure 11 will generally be vertical and perpendicular to the face of the pillar as shown in Figure 10. The tensile stress zone is located around the center of each pillar face and thus cracks will generally not extend to the roof and floor. Prior to oil fill, the maximum tensile stress calculated on the pillar faces is approximately $2.5 \mathrm{MPa}$ (363 psi) with an average of approximately $1.8 \mathrm{MPA}$ (260 psi). The tensile strength of Weeks Island salt was tested in the laboratory using the indirect or Brazilian method as part of the geotechnical studies performed in 1979 to evaluate the suitability of the site for oil storage. A series of tensile strength measurements were made on lower level core. The average tensile strength of clean salt was measured as $155 \mathrm{psi}$ with a standard deviation of 48 psi. Salt with impurities had an average tensile strength of 280 psi with a standard deviation of 105 psi.[4] The test results show that the presence of impurities significantly increases the tensile strength of Weeks Island salt. An examination 
of pictures taken in the upper and lower levels shows considerable banding in the salt produced by interlayering of impure and clean salt. Thus, there is considerable spatial variation of the salt tensile strength. The simulation is predicting tensile stresses that may exceed the mean strength of both impure and clean salt. Thus, some of the observed cracking seen can be attributed to tensile stresses exceeding strength. Corner spalling is commonly observed in salt mines and could be caused or enhanced by intersecting tensile cracks originating on two different adjacent orthogonal faces. Another possible mechanism for spalling of the pillar corners and faces the will be discussed later.

Figures 12 and 14 are photographs taken during the 1977 inspection that show the principal-stress type of tensile cracking predicted by the finite element model and illustrated schematically in Figure 11. Figure 13 indicates vertical cracking orthogonal to the pillar face that does not extend to the roof and floor. At pillar corners, where the cracks intersect, long vertical pieces of salt may separate from the pillar as shown in Figure 14. Figure 15 illustrates the type of slabbing the model predicts possible in the roof of the mine. Compare this photograph with the type of predicted roof slabbing depicted in Figure 12. This type of roof decay was not extensive in the DOE facility and also does not appear much in the Markel Mine indicating that the Weeks Island salt does have some in-situ tensile strength. The model predicts a maximum tensile stress in the roof of approximately 1.0 $\mathrm{MPa}$ (145 psi). This is in the range of the measured tensile strength of the salt which indicates that some roof failure may occur but that it is not likely to be extensive. This condition is observed in the mine and adds some validity to these calculations. 


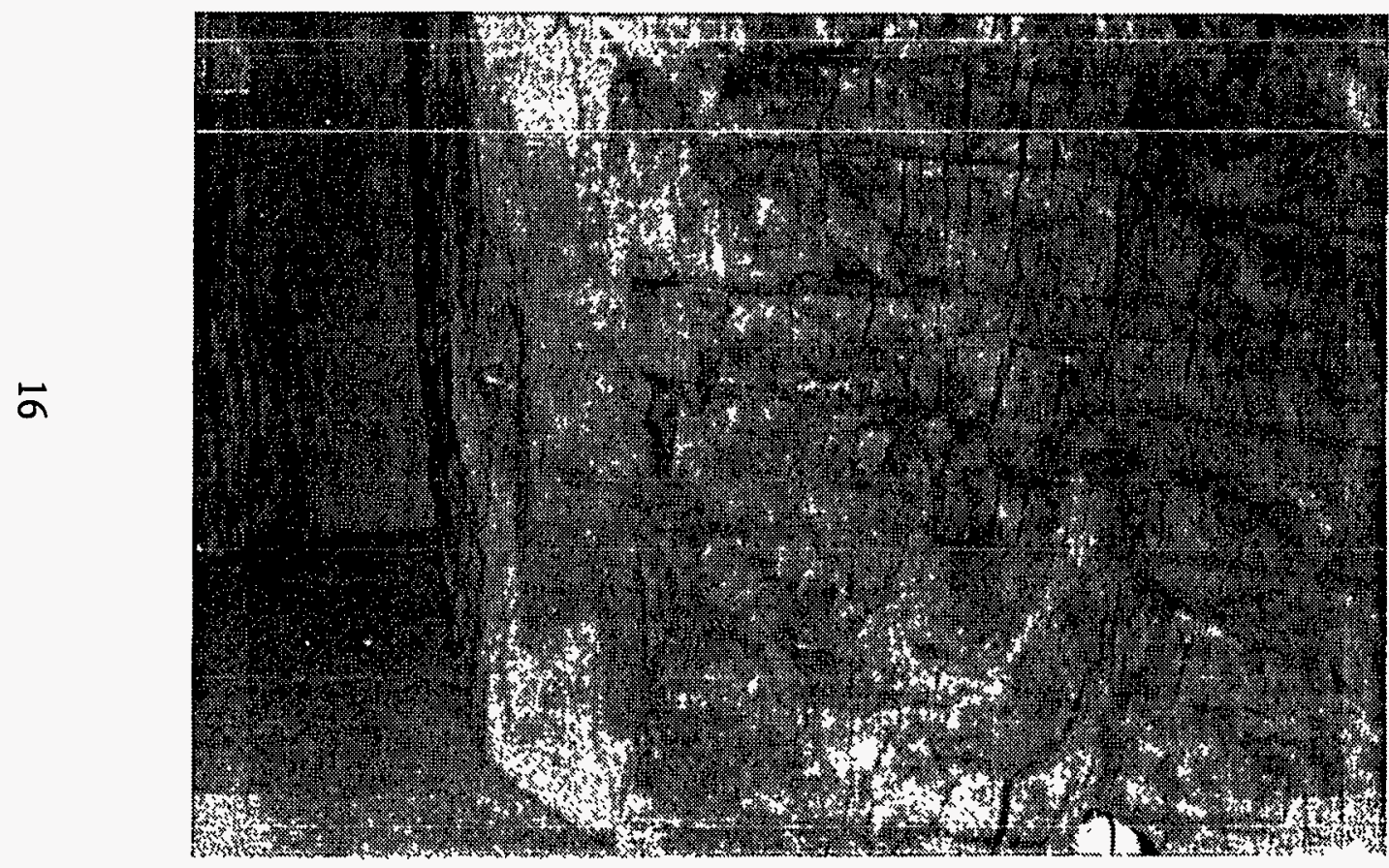

Figure 12. Vertical Pillar Cracks Likely Caused by Tensile Stresses (Intersection C13 of Upper Level - Northeast Corner

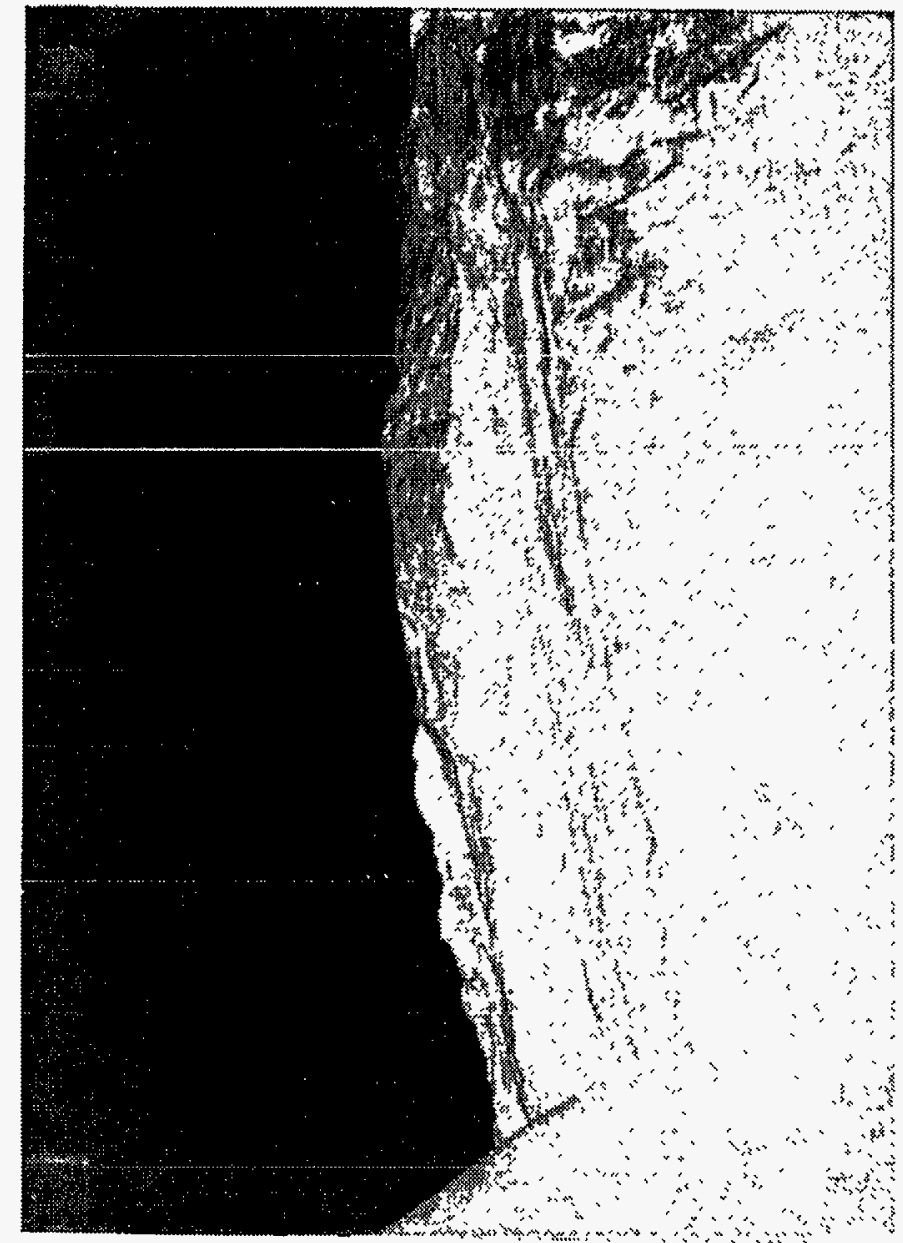

Figure 13. Salt Detaches at Pillar Corners Where Tensile Cracks Intersect (Intersection F14 of Upper Level. 


\subsection{Creep Strain Induced Salt Fracture}

Another cracking/fracturing mechanism evaluated during this simulation is related to the accumulation of creep strain. This mechanism is numerically evaluated using a fracture function that was developed in the early 1980's for accessing salt cavern stability [8]. Coefficients for this fracture function have been generated for Weeks Island salt from quasi-static triaxial compression tests performed by RE/SPEC in 1977. [1]. The coefficients are based on the relationship between the ultimate strain and the mean stress (pressure) in each specimen at the time of failure as given in Table 3 .

\section{Table 3: Weeks Island Quasi-Static Compression Tests}

\begin{tabular}{|c|c|c|c|}
\hline 19est: & $\begin{array}{l}\text { Radiral Conffiring } \\
\text { Stresstprit: }\end{array}$ & 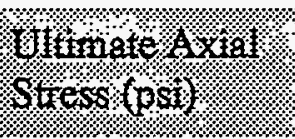 & 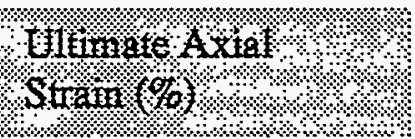 \\
\hline 1 & 0 & 2520 & 1.8 \\
\hline 2 & 0 & 1950 & 2.5 \\
\hline 3 & 0 & 1235 & 1.6 \\
\hline 4 & 0 & 2360 & 2.6 \\
\hline 5 & 500 & 8170 & 10.04 \\
\hline 6 & 500 & 7320 & 12.61 \\
\hline 7 & 500 & 7300 & 16.22 \\
\hline 8 & 1000 & 9450 & 20.23 \\
\hline 9 & 1000 & 9220 & 21.80 \\
\hline 10 & 1000 & 8830 & 27.02 \\
\hline
\end{tabular}

Even though the fracture function is documented in Reference [8], it will also be presented here for completeness. The ultimate axial strain can be related to the mean confining pressure (Table 3) using the method of least squares. The resulting expression is

$$
\varepsilon_{f}=1.15+\left(1.0 \times 10^{-5}\right) P^{1.7614}
$$

where $\varepsilon_{f}$ is the ultimate strain where fracturing occurs and $P$ is the mean stress (pressure). Figure 14 compares the above equation to the triaxial test data from Table 3. 


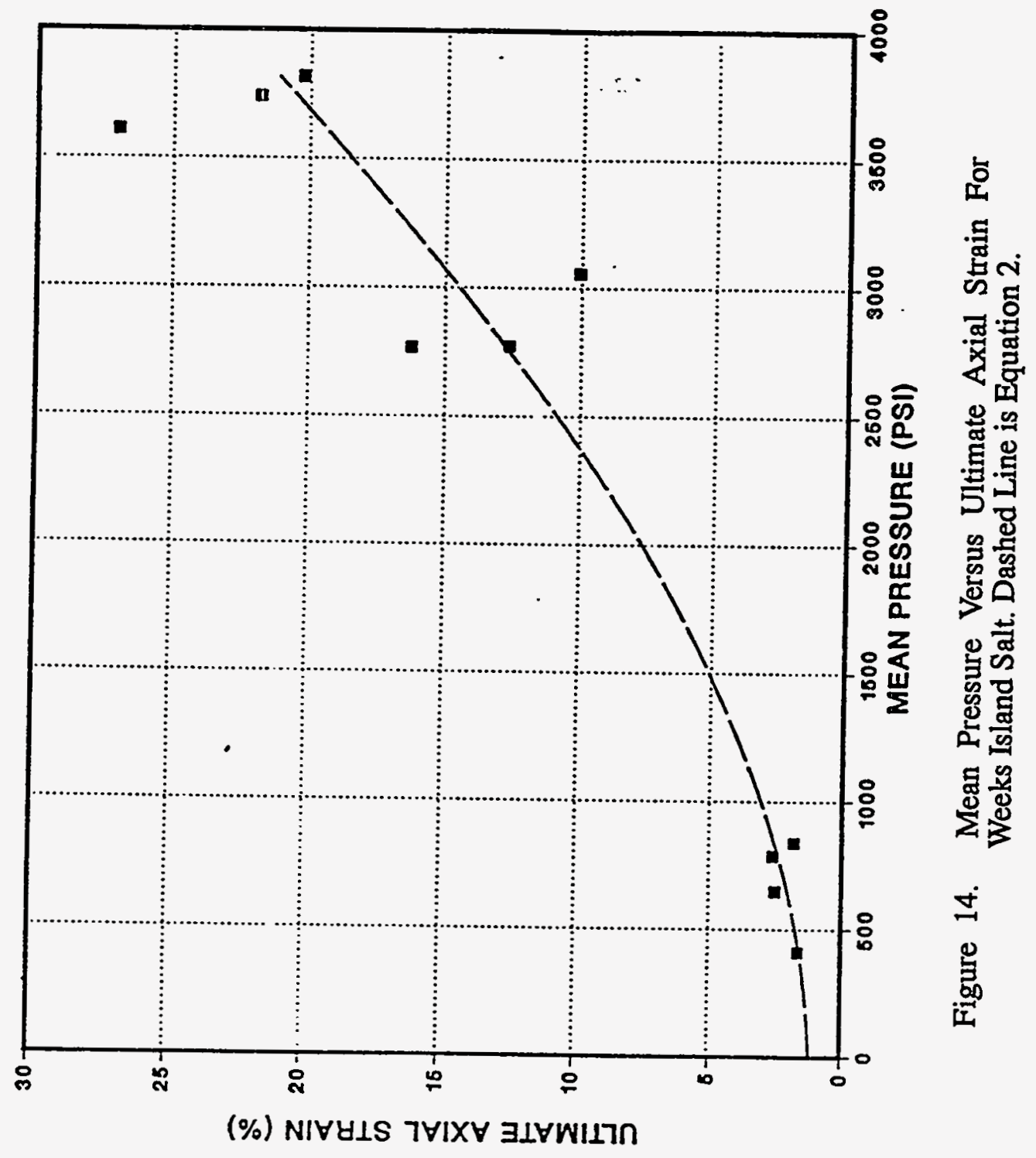


To generalize the triaxial test data, the pressure, $P$, is computed by

$$
P=\left(\sigma_{1}+2 \sigma_{3}\right) / 3
$$

The status of fracture in the model is calculated for plotting purposes by taking the ratio of the fracture strain $\varepsilon_{f}$ and the accumulated creep strain $\varepsilon_{a}$ in each finite element.

$$
\phi=\frac{\varepsilon_{f}}{\varepsilon_{a}}
$$

Fracture is likely to occur if $\phi$ is less than 1.0.

A spatial distribution of the fracture function for each time-step is obtained by postprocessing the finite element creep analysis and using the calculated stresses and strains for each element in equations 1 through 4. Stability of the pillars in the oil storage facility can be evaluated using the spatial distribution as a function of time. Since the ultimate strain (Table 3 ) is from quasi-static and not creep tests, the fracture criterion is considered conservative. A similar exercise was done for other salts, where the ultimate strain from quasi-static compression tests was empirically related to mean [6] and confining pressures[8]. Reference [8] also compared the predicted ultimate strains from a quasi-static based criterion to strains measured in creep and extension tests to verify the tenet that the quasi-static based criterion is a conservative lower bound approximation.

Salt cracking/fracturing predicted by the finite element model with fracture function postprocessing can be qualified to some extent by comparing computational results with photographs from the mine. These photographs, presented in Figures 15 through 30, were taken during the 1977 inspection, which was the last visual account of the condition of the mine prior to clean-up and oil fill. Photographs from the 1977 inspection are presented here to increase confidence in the predictions made by the finite element simulation and also to illustrate the general condition of the mine at that time. A number of photographs are included to show that the fracturing mechanisms predicted were prevalent throughout the mine and not isolated occurrences. Quotes from the inspection report are given below along with descriptions of the photographs.

The 1977 investigation reported pillar decay ranging from minor to severe. The majority of the upper level was rated as severe, defined by the following statements: 1) "Extensive pillar slabbing of 8' to 15 ' thickness." 2) "Slabs may be exfoliated or tapered to a wide base." 3) "Extensive ravelled salt piles (up to 40' high) covering the width of the room." 4) "Area generally considered unsafe for personnel." Approximately 30 percent of the lower level pillars were rated as severe decay, primarily those in the south central region of the mine. The following statements were also included in the report. "The general mode of pillar decay is essentially by spalling and was observed in all sections of the mine which 
are older than about two years." "Creep rupture is the most commonly observed type of pillar decay in the Weeks Island mine." "Ravelling and pillar decay is a continuing process that is audible in many rooms at the lower level. Several intact pillars were observed in the older 75-ft rooms, however, these are relatively uncommon." "The roof in both levels is in relatively good condition." "Pillar decay can visually be separated into two types of spalling: exfoliation and slabbing." Exfoliation means casting off laminae or splinters. Figures 15 through 19 show exfoliation behavior within rooms and at pillar corners. Quoting from the report, "exfoliation was observed to occur parallel to the nearly vertical foliation", whereas "slabbing was observed to occur across the bedding." Slabbing is shown in Figures 20 through 25 within rooms and at pillar corners. Slabs can separate from the pillar and fall as large pieces of salt. Exfoliation also results in accumulation of grainsized salt in piles. The differences are shown in Figures 26 through 30.

The calculated spatial distribution of the fracture function on the finite element model for the years 1977, 1993, 2000 and 2030 are shown in Figures 31 through 34 respectively. The numerical ends of the gray scale in these figures have been adjusted to give the approximate slab thicknesses observed on the upper and lower levels of the mine during the 1977 inspection. Hunsche [9] noted that a pillar fractured completely through will still only spall around the outer perimeter. Hunsche conducted a test where a salt pillar was loaded to failure and ultrasound was used to measure the integrity of the pillar core. The core of the pillar was found to have significant strength degradation while only the outer edges were spalling. Thus, it is difficult to know the actual condition of the core of the SPR pillars at the time of the 1977 inspection. The spatial distribution of the fracture function, $\phi$, shown in Figures 31-34 may represent the point where fracturing manifests itself as spalling. It is important to point out that the fracture function calculated here was post-processed after the calculation was completed. Therefore, regions where salt fracture is indicated do not experience any reduction of strength or modulus in the model. In this regard, the simulation is not conservative as salt fracturing softens its mechanical response and its ability to carry load. The load would probably be transferred to the more competent salt in the core of the pillar. Pillar yielding and reduction of load-carrying capability would result from strength reduction and would also manifest itself on the surface as increased subsidence rates. As expected the predicted subsidence rate (Figure 5) for the model does not increase with time because material strength is not reduced with increases of the fracture function since it is post-processed. Increases in the measured subsidence rate would be one indication that pillar yielding is occurring. The measured subsidence data from surveyed benchmarks over the mine since 1983 does not, at this time, show an acceleration of the subsidence rate over the mine.

It is important to point out that the cracking/fracturing generated by creep strain accumulation and quantified by the fracture function in the model will be directionally controlled by the prevailing orientation of the maximum principal stress field as illustrated in Figure 10. Thus, fracturing induced by accumulation of creep strain will produce exfoliation, slabbing, corner detachment and piles of exfoliated salt as documented by the photographs in Figures 15 through 30. Creep-induced fracturing will also occur when the salt is in a general state of compression and the orientation of the fracturing will be as indicated in Figure 10. This is a very different conclusion than that reached in the original 
evaluation of the Weeks Island mine in 1977 [1] when it was concluded that the mine would be stable with increasing time. This conclusion was based on linear, and somewhat less sophisticated finite element models, that predicted that the pillars would exfoliate and slab off their tensile stress regions and that the remainder of the pillar would be in compression and would therefore remain stable. Advances in laboratory testing of rock salt and computational methods for modeling rock salt constitutive behavior now point to the fact that the pillars will continue to crack and fracture in compression due to accumulation of creep-induced strain. This will lead to continued progressive structural degradation of the pillars.

The time dependent nature of the creep strain induced failure of the mine is very important. It is evident from Figure 31 that the mine would be considered basically stable in 1977 when the inspection was completed since only a portion of pillar is fractured. However, Figure 32 indicates that, according to the same criterion, by 1993 fractures have propagated completely through the pillar on the lower level. A pillar in this condition would probably have very little load carrying capability remaining. It is not known whether the additional fracturing predicted by the analysis results in more spalling of the pillars or complete deterioration. However, this fracture criterion indicates that the condition of the mine will continue to worsen as the pillars accumulate creep strain over the years. The upper level pillar is predicted to be fractured completely through by the year 2010 . 

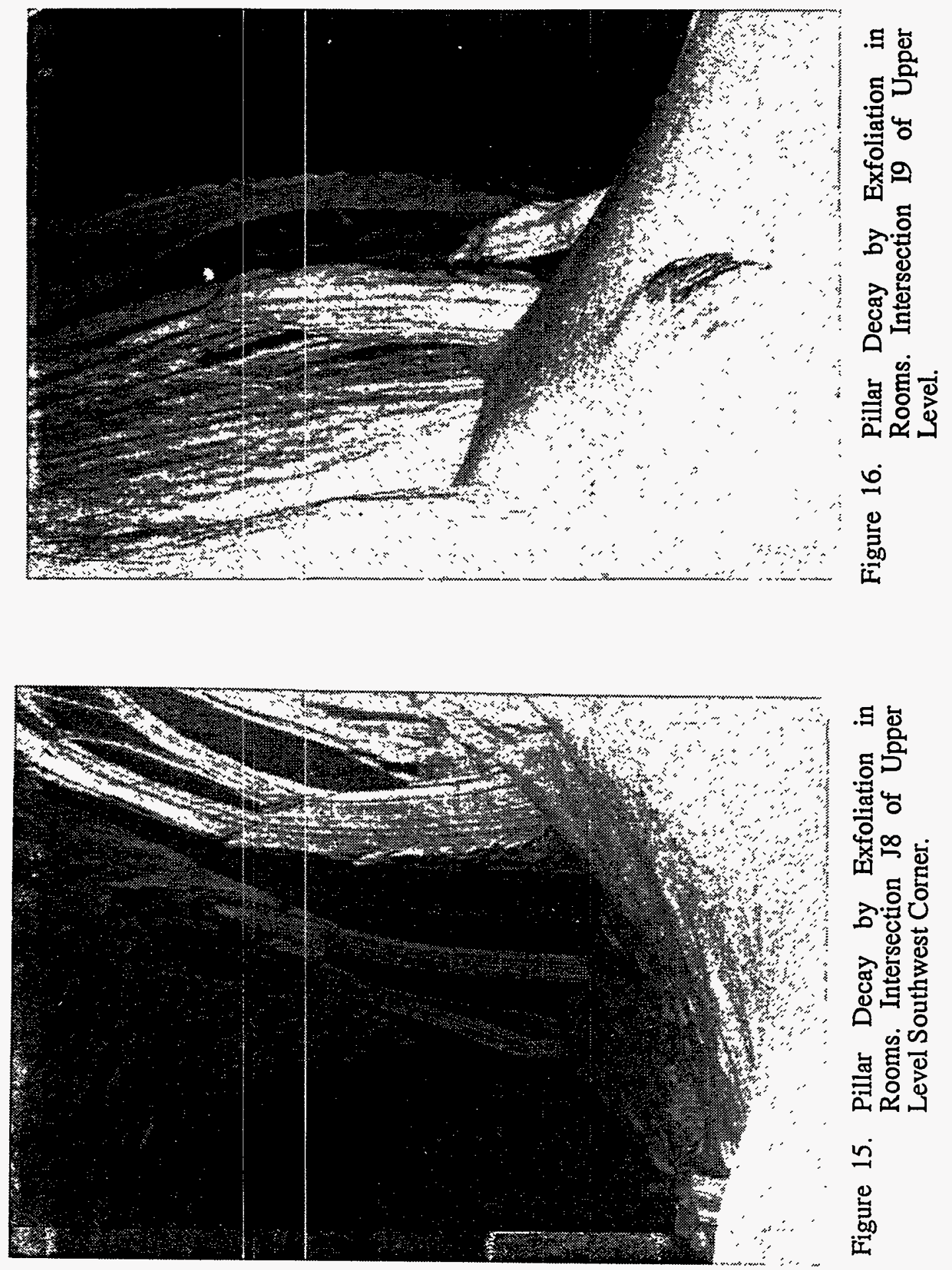


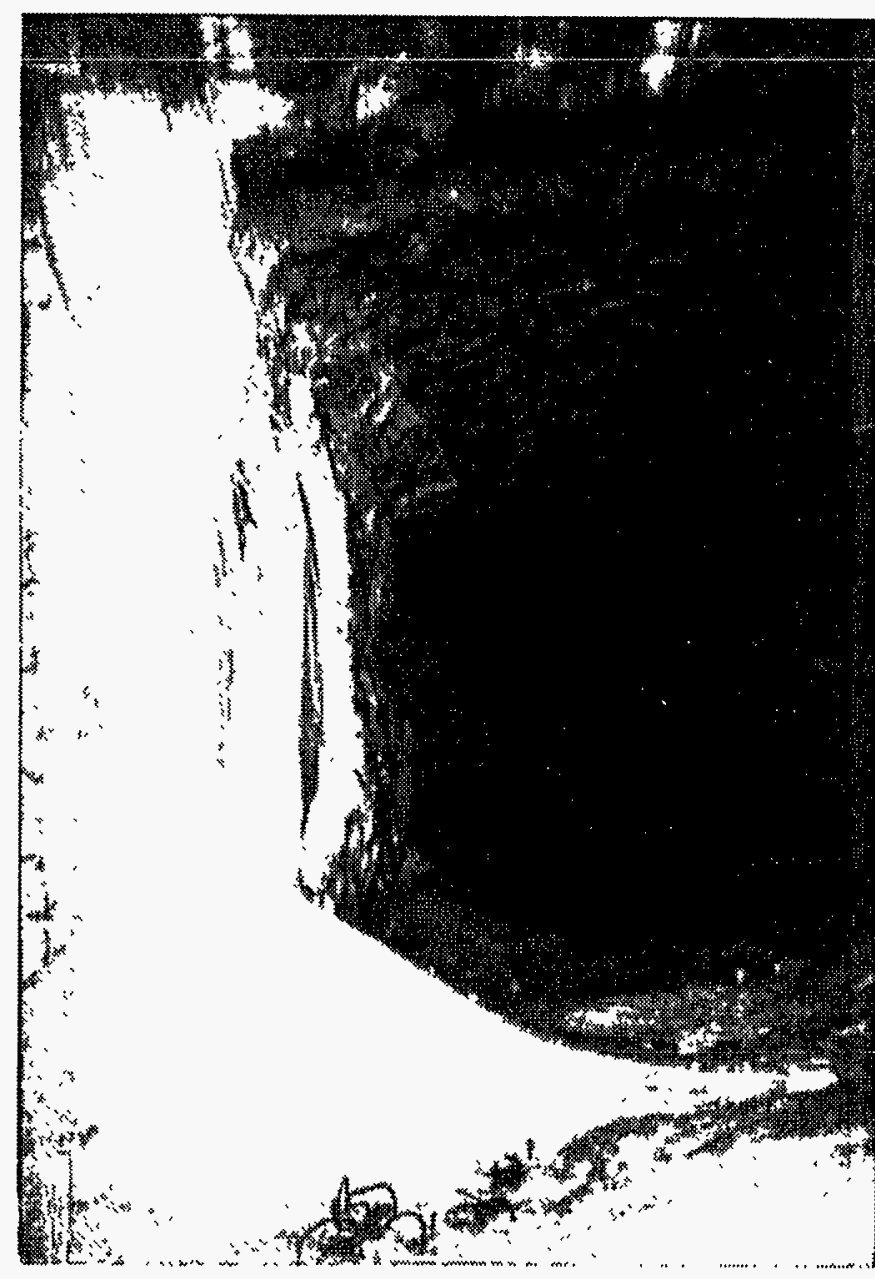

Figure 17. Pillar Decay by Exfoliation in Rooms. Intersection K10 of Upper Level Southeast Corner.

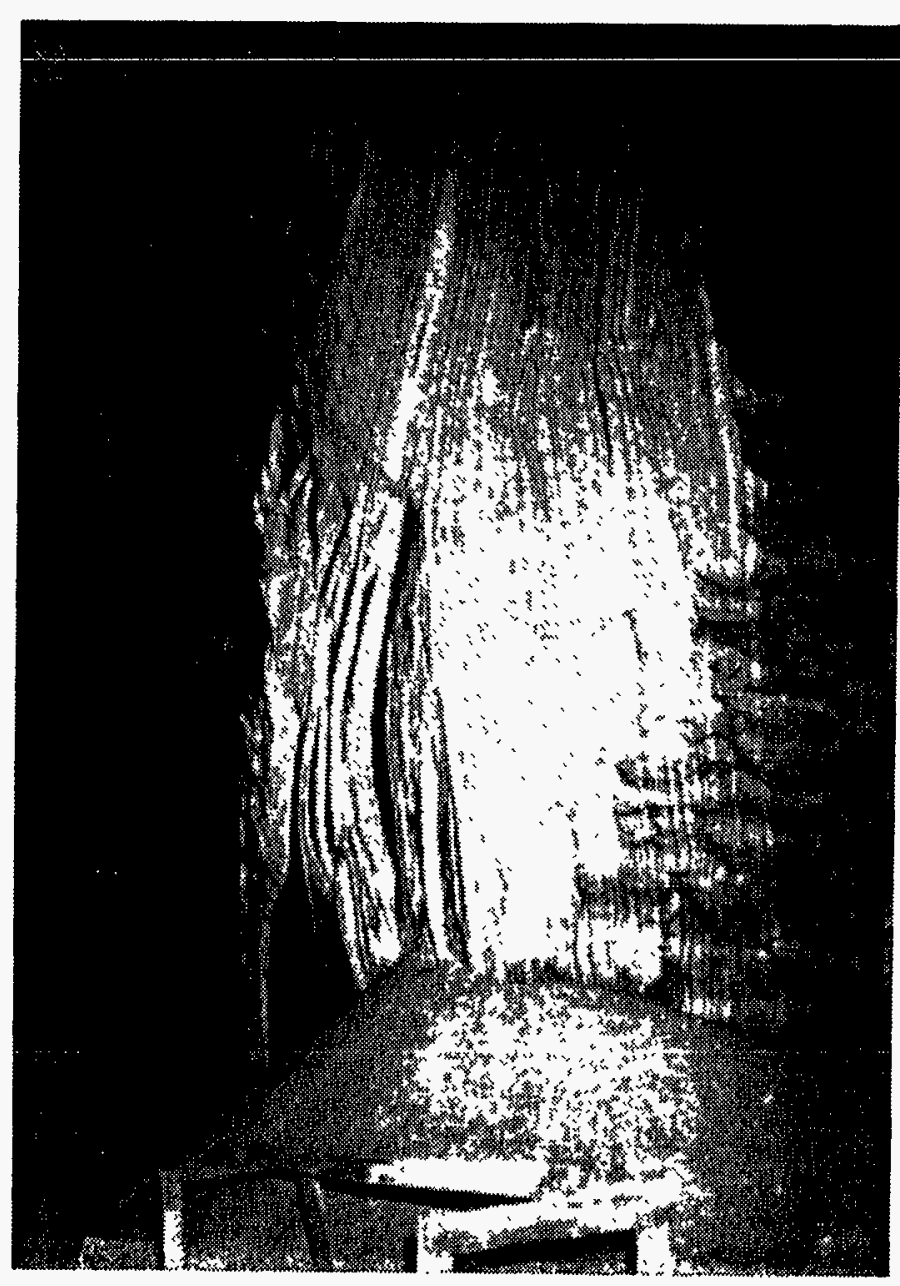

Figure 18. Pillar Decay by Exfoliation at Corners. Intersection K7 of Upper Level Southwest Corner. 

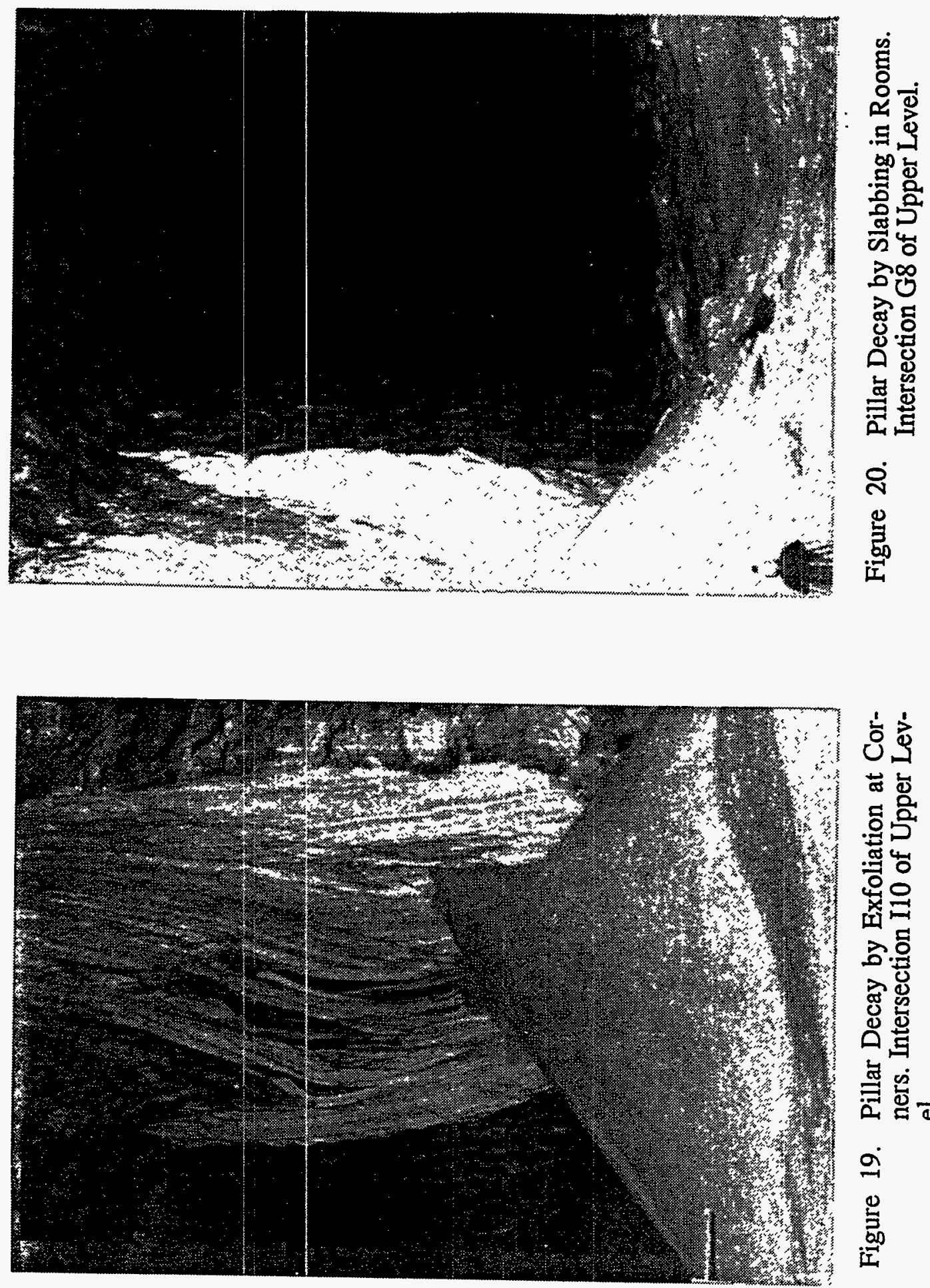

형 Ш 호음 역 핮을 그윰 灾

ర్

口志 总嵒 i 0 and 


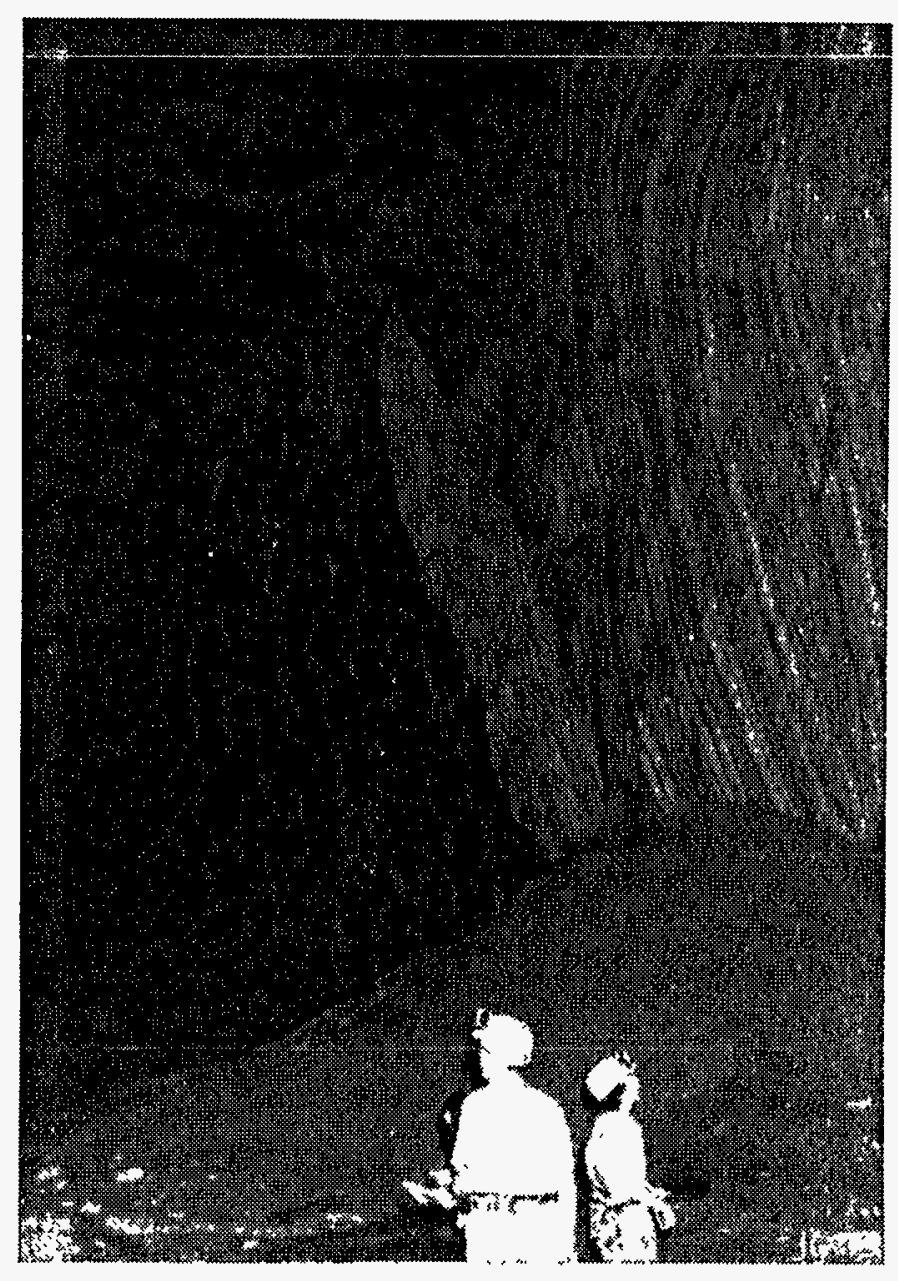

Figure 21. Pillar Decay by Slabbing in Rooms. Room J Between Crosscuts 12 and 13 of Upper Level.

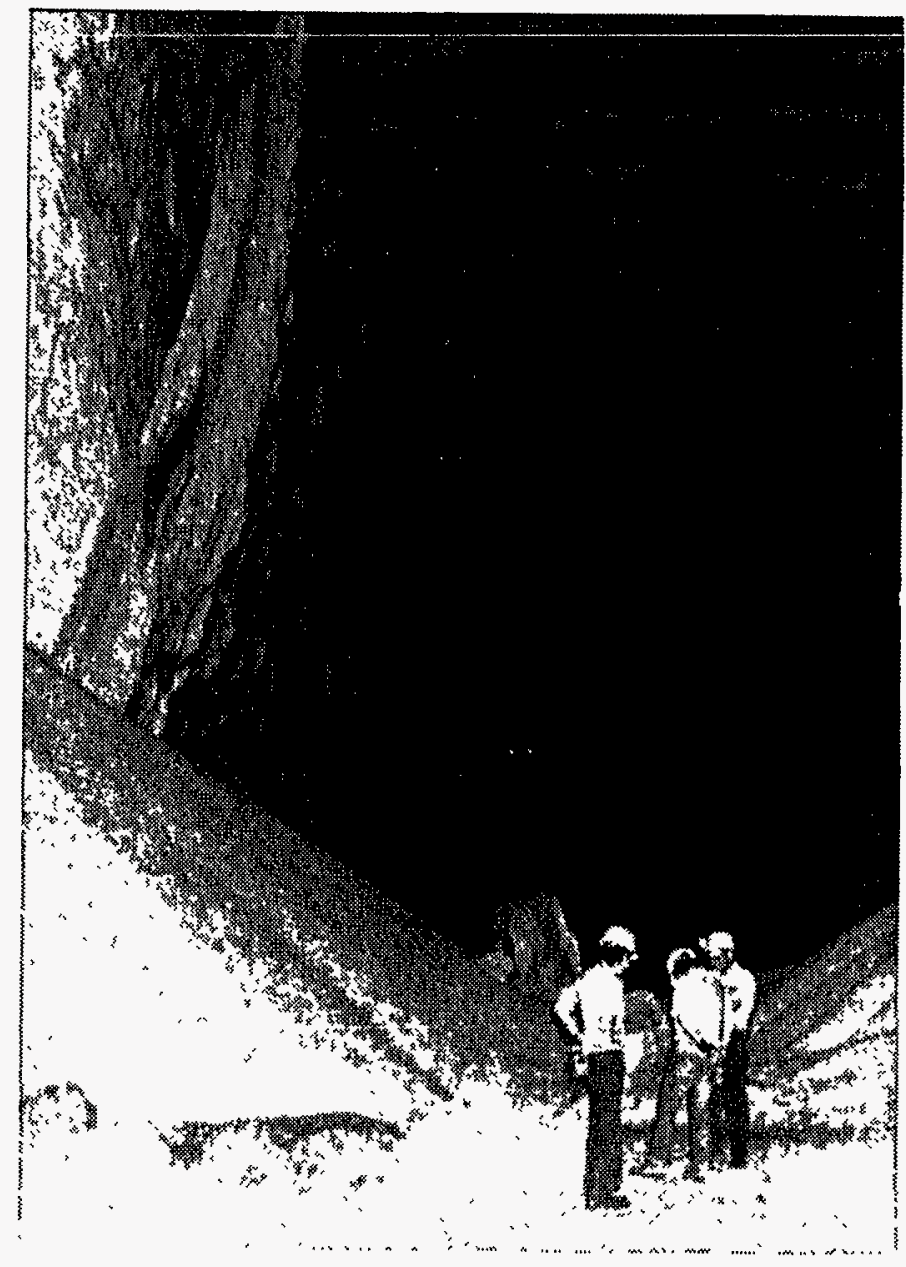

Figure 22. Pillar Decay by Slabbing in Rooms. Room H Near Crosscuts 10 of Upper Level. 

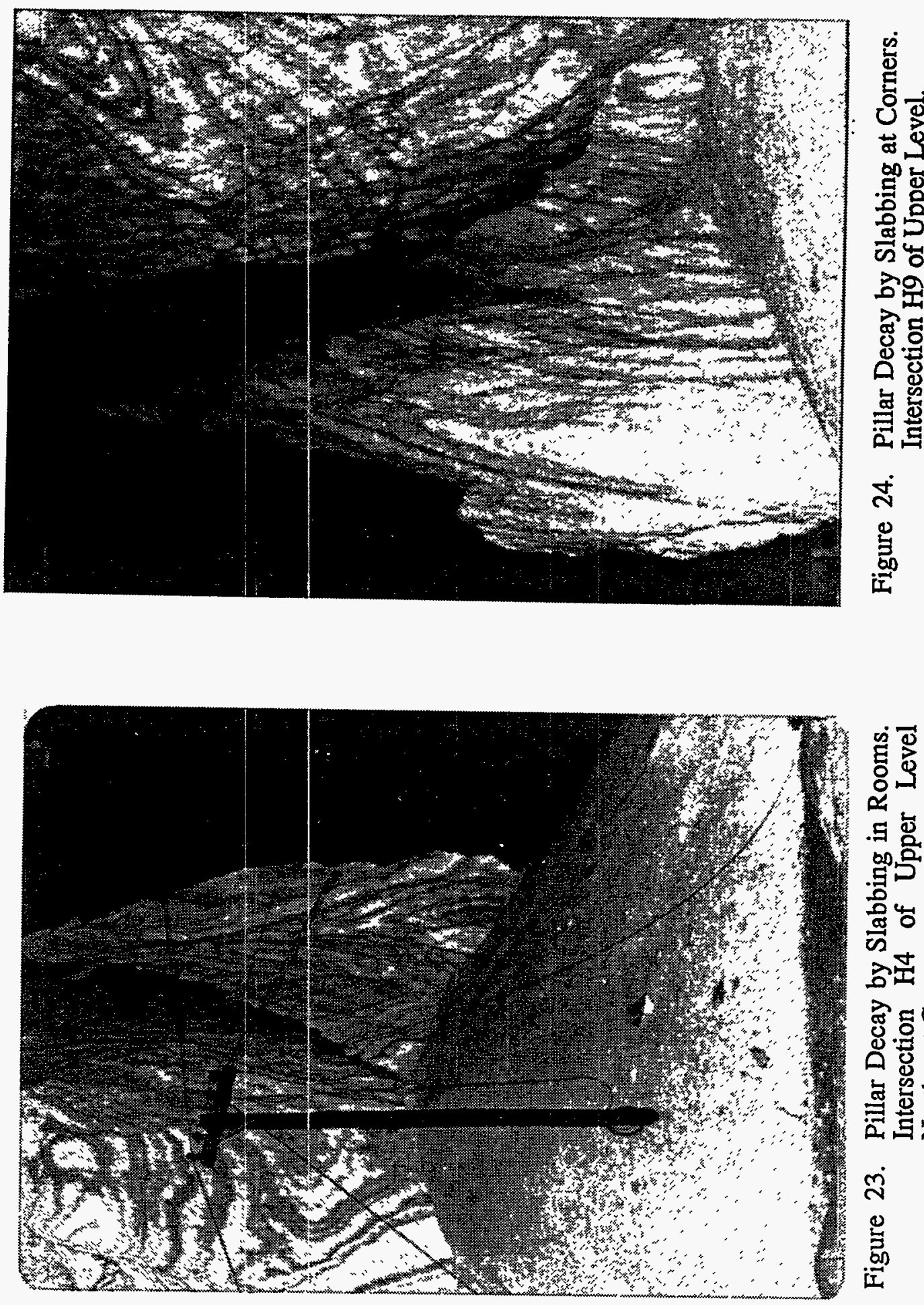

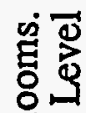

$\alpha$

.

옹

句

ज

宫茫

希

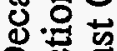

A

층

沓昰家

ஸे

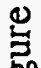

票

诖 


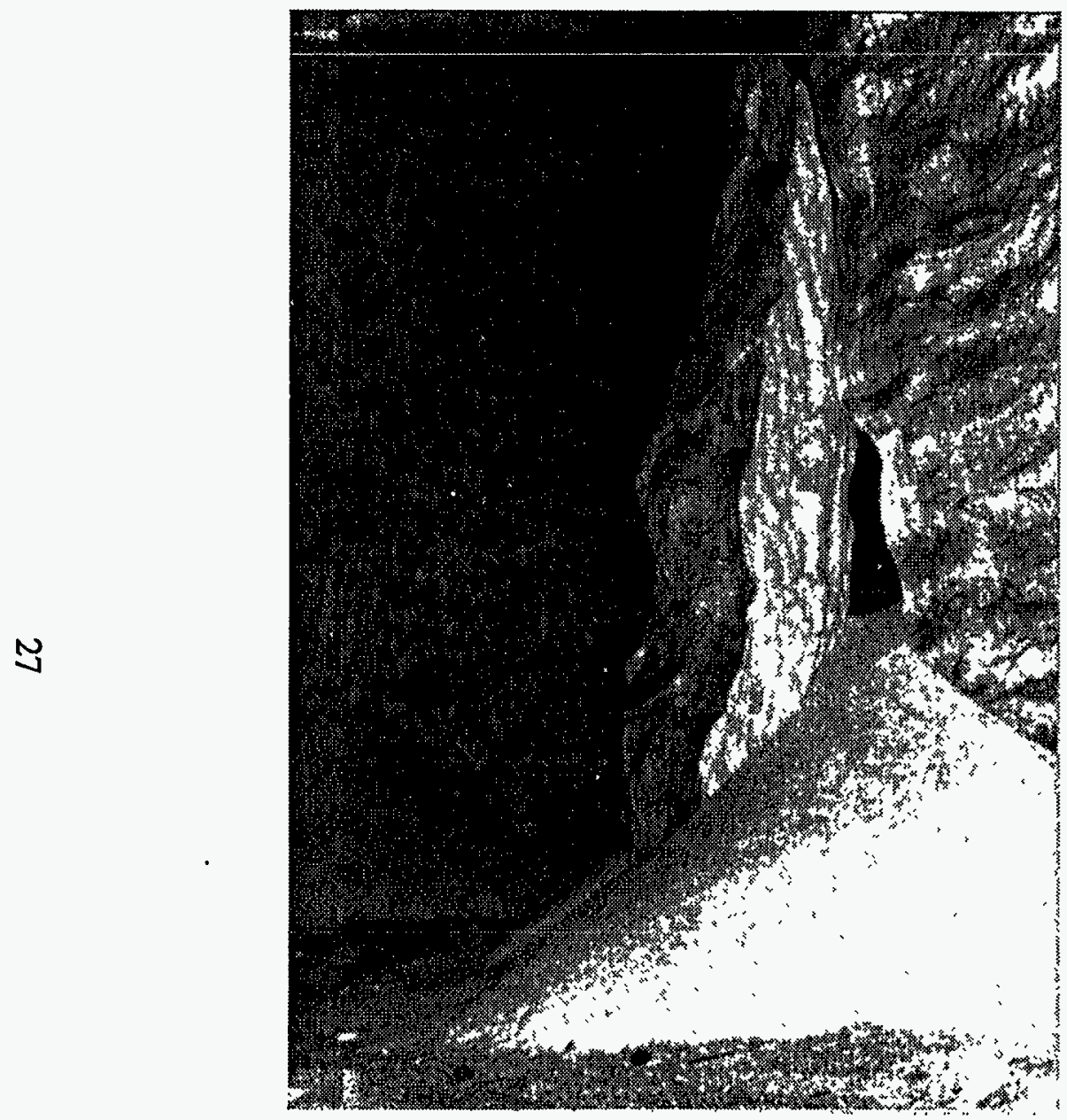

Figure 25. Pillar Decay by Slabbing at Corners. Intersection J9 of Upper Level Southwest Corner.

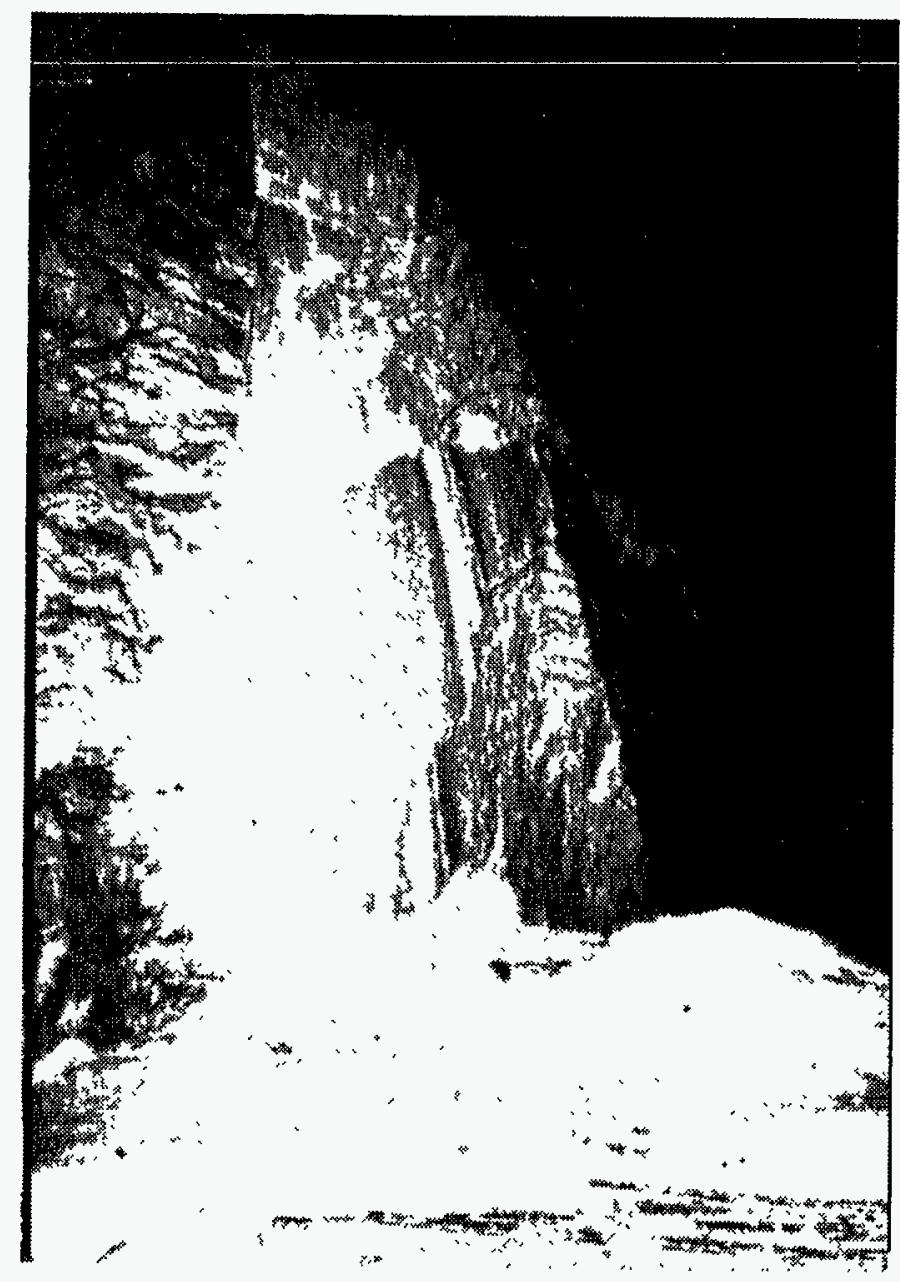

Figure 26. Piles of Ravelled Salt from Exfoliated Pillars. Room A Between Crosscuts 5 and 6 of Upper Level. 

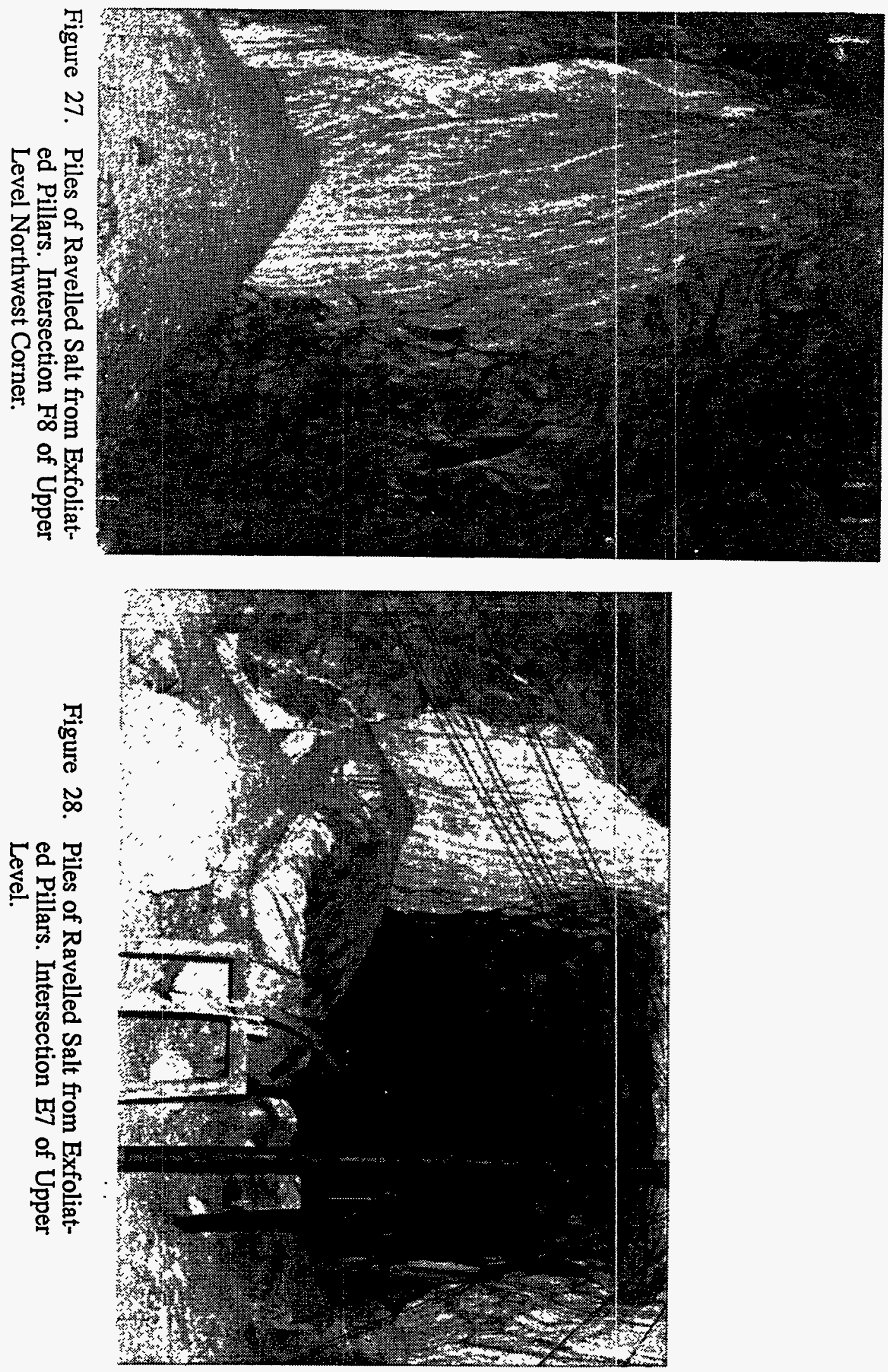

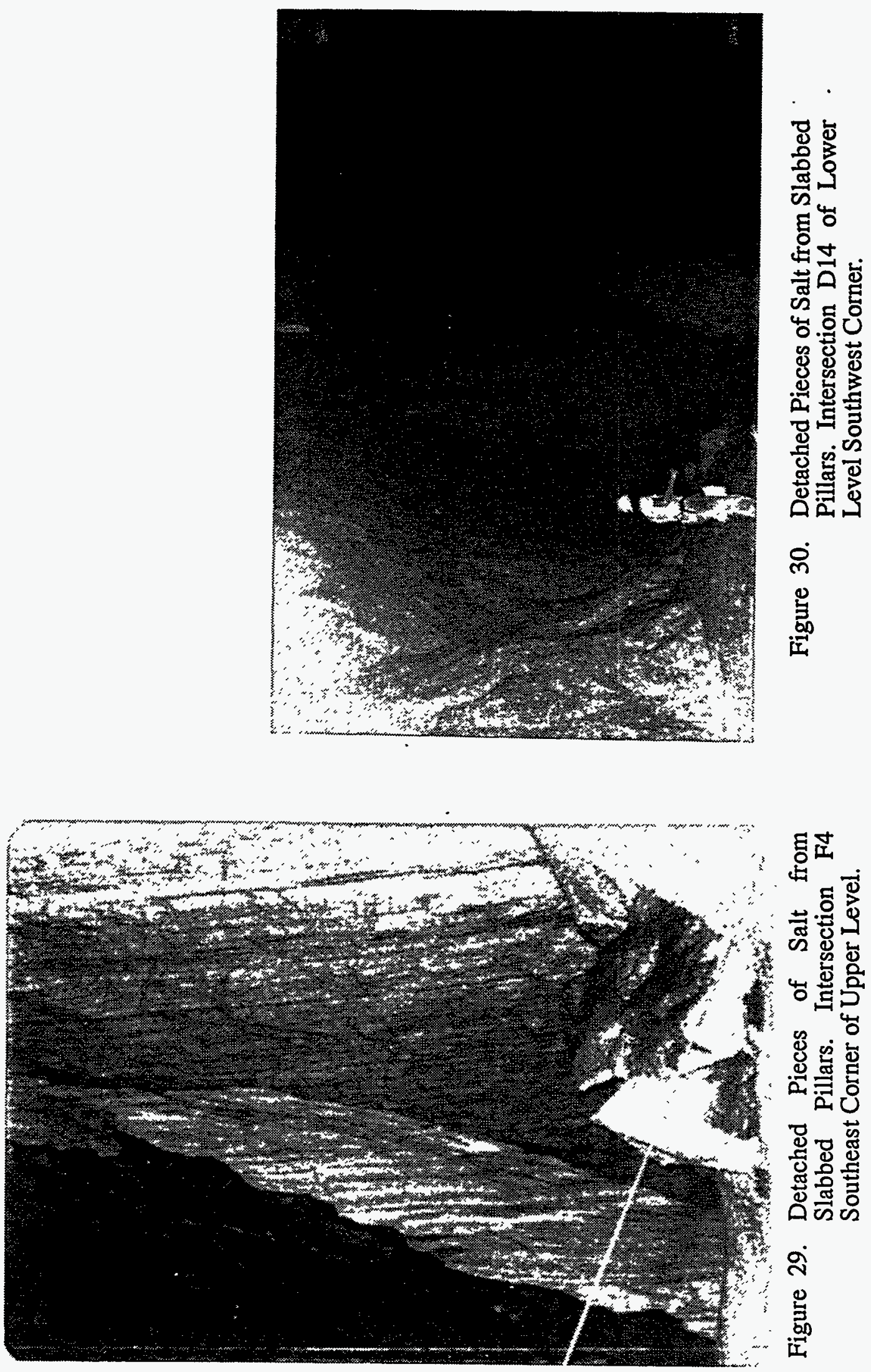


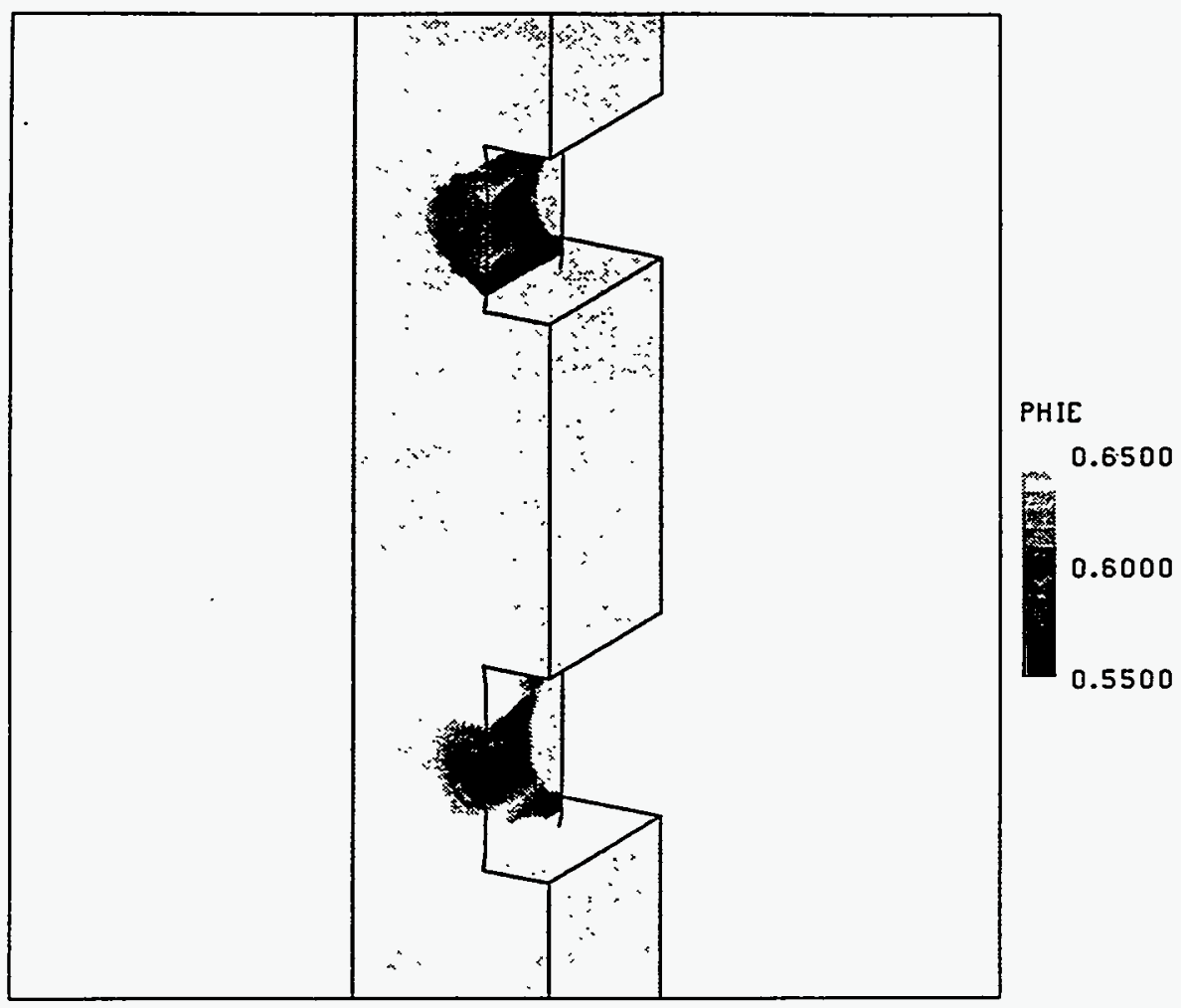

Figure 31. Calculated Spatial Distribution of Fracture Function (Year $=$ 1977). Dark Area Indicates Extensive Fracturing.

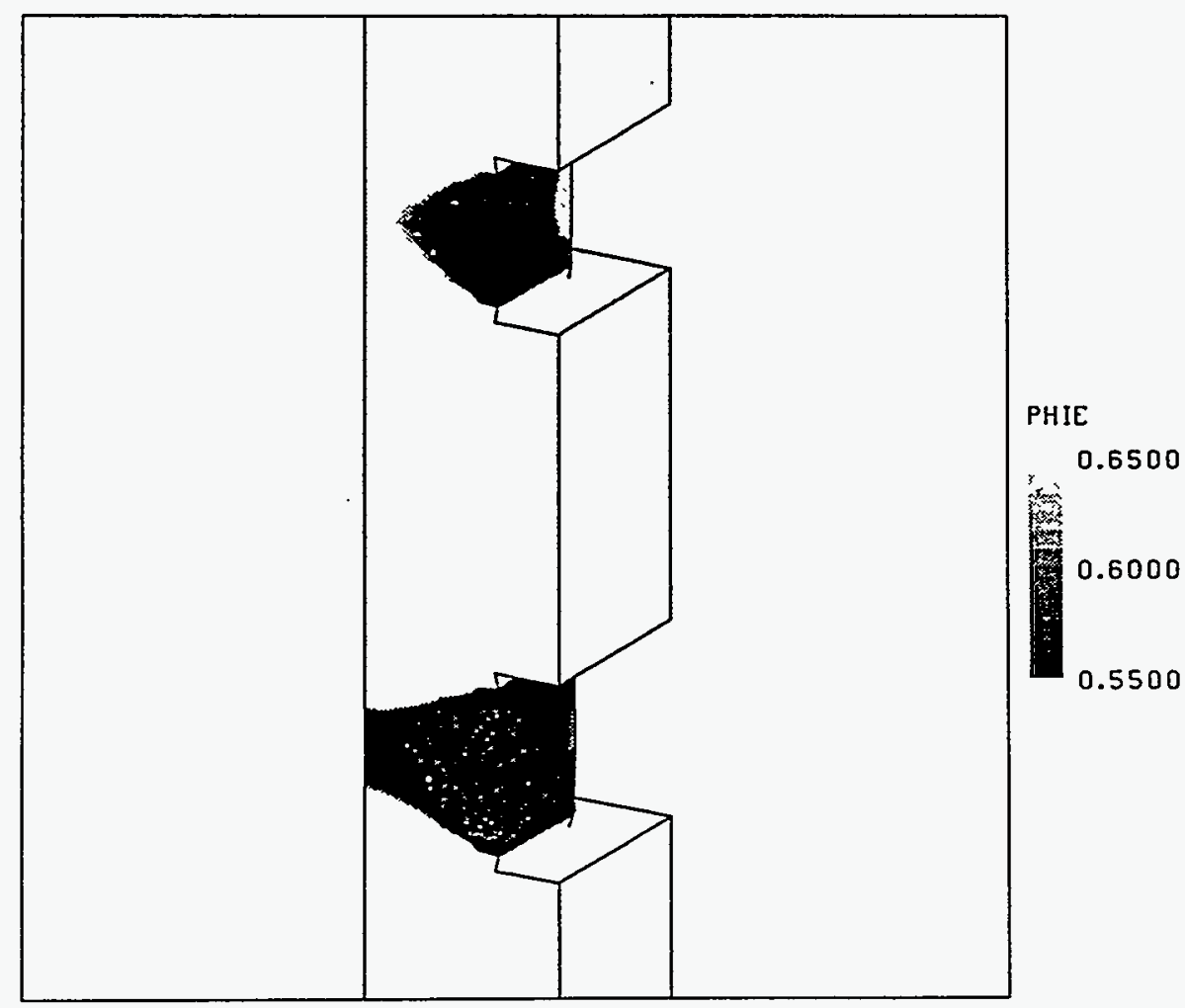

Figure 32. Calculated Spatial Distribution of Fracture Function (Year = 1993). Dark Area Indicates Extensive Fracturing. 


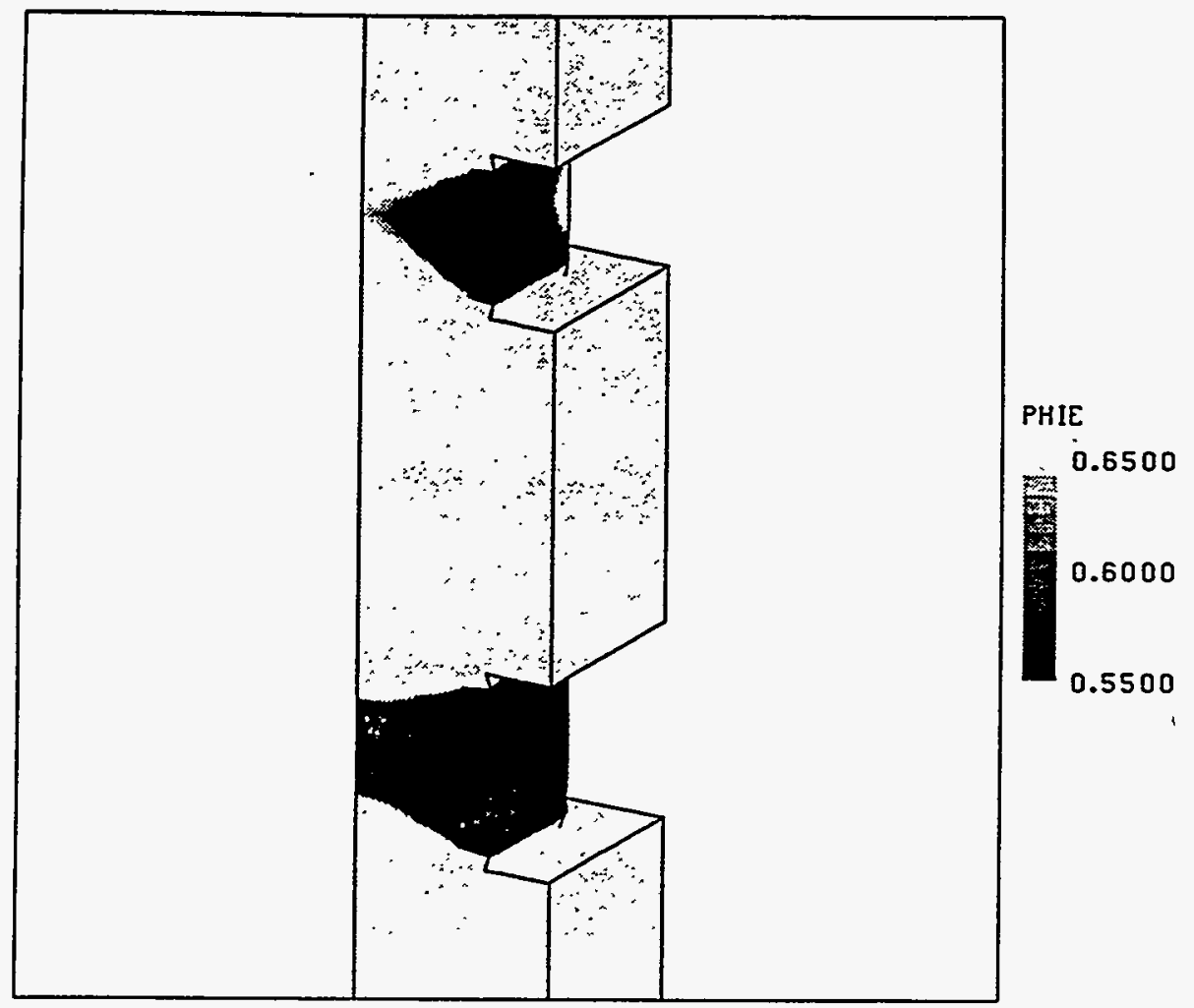

Figure 33. Calculated Spatial Distribution of Fracture Function, Year $=2000$. Dark Area Indicates Extensive Fracturing.

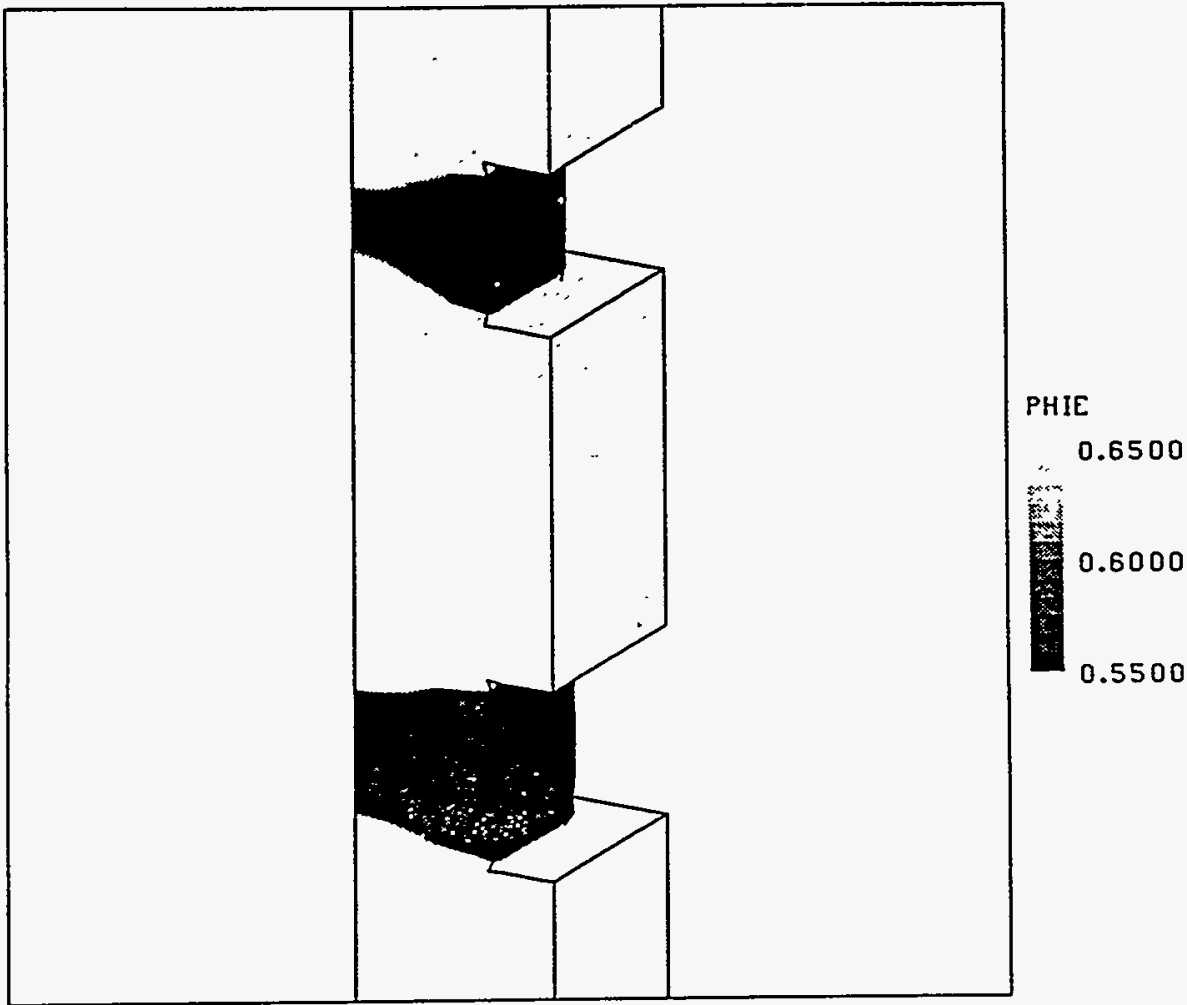

Figure 34. Calculated Spatial Distribution of Fracture Function, Year $=2030$. Dark Area Indicates Extensive Fracturing. 


\subsection{Conclusions}

A state-of-the-art structural mechanics computer simulation of the Weeks Island SPR oil storage facility has been completed. The model included both upper and lower levels and treated the mine history. Model results have been verified to the extent possible by favorable comparison with subsidence measurements and photographs documenting the mine condition in 1977. The two mechanisms of salt fracture demonstrated in this simulation are tensile fracture and creep strain induced fracture. Both mechanisms produce fracturing that results in exfoliation and slabbing from the faces of the pillars as well as corner detachment. The 1977 inspection photographs show evidence of the predicted fracture mechanisms in abundance. A major difference between the two mechanisms is that tensile fracturing occurs early in the mine history and does not worsen with time whereas creep strain fracturing is progressive and time-dependent. The model indicates that time-dependent progressive failure of the pillars at the center of the mine is probably occurring due to creep strain fracturing. This does necessarily not mean that the entire mine is in danger of sudden collapse. The time-dependent nature of salt will cause a slow deterioration of the mine starting with the older pillars and pillars in the center and working outwards. The time at which the mine stability endangers the stored oil is difficult to determine exactly but large scale pillar degradation should result in an increase in the surface subsidence rate and this has not yet been reflected in the subsidence data for the site. This study suggests that the mine will not be suitable for oil storage indefinitely.

\section{References}

[1] Weeks Island Mine Geotechnical Study, Acres International Inc., Buffalo, NY, November, 1977, Contract FEA-1251-75.

[2] Calculation of Creep-Induced Volume Reduction of the Weeks Island SPR Facility Using 3-D Finite Element Methods, Dale S. Preece, Sandia National Laboratories, SAND87-1694, September, 1987.

[3] 3-D Finite Element Calculation of Subsidence Induced Deformation of the Weeks Island Service Shaft, Dale S. Preece, Sandia National Laboratories, SAND87-2365, December, 1987.

[4] Weeks Island Mine Additional Geotechnical Studies, Acres International Inc., Buffalo, NY, October, 1979, Contract FEA-1251-75.

[5] Annual Subsidence Report - Fiscal Year 1992, Boeing Petroleum Services Inc. Publication No. D506-03165-09, October, 1992.

[6] Reference Stratigraphy and Rock Properties for the Waste Isolation Pilot Plant (WIPP) Project, R. D. Krieg, SAND83-1908, Sandia National Laboratories, January, 1984. 
[7] Investigation of an Empirical Creep Law for Rock Salt That Uses Reduced Elastic Moduli, H. S. Morgan and R. D. Krieg, Proceedings of the 31st U. S. Rock Mechanics Symposium, June, 1990.

[8] Leached Salt Cavern Design Using a Fracture Criterion for Rock Salt, D. S. Preece and W. R. Wawersik, 25th U. S. Symposium on Rock Mechanics, Northwestern University, June 1984.

[9] Discussion of Rock Salt Pillar Failure Mechanisms, Udo Hunsche, during a visit to Sandia National Laboratories, July 1993.

[10] JAC3D - A Three-Dimensional Finite Element Computer Program for the Nonlinear Quasi-Static Response of Solids with the Conjugate Gradient Method, J. H. Biffle, Sandia National Laboratories, SAND87-1305, February, 1993. 


\section{DISTRIBUTION:}

7 US DOE SPR PMO 900 Commerce Road East New Orleans, LA 70123

Attn: J. Culbert, FE-4431 (3)

J. Kilroy, FE-433

J. Kunkle, FE-4422

R. Meyers, FE-4422

L. Rousseau, FE-443

3 US DOE SPR 1000 Independance Avenue SW Washington, DC 20585

Attn: D. Johnson, FE-421

R. Smith, FE-423

D. Buck, FE-421

4 Dyn McDermott Petroleum Op. 850 S. Clearview Parkway New Orleans, LA 70123

Attn: T. Eyerman, EF-20

J. McHenry, EF-20

K. Mills, EF-20

K. Wynn, EF-20

3 Weeks Island SPR Site

P. O. Box 434

New Tberia, LA 70560

Attn: M. Jackson

R. Phillips

M. Bertoldi

1 RE/SPEC Inc.

3824 Jet Drive

Rapid City, SD 57709

Attn: Joe Ratigan

Sandia Internal:

1517 H. S. Morgan, MS 0433

1517 E. L. Hoffman, MS 0433

6100 R. W. Lynch, MS 0701

106113 J. K. Linn, MS 0706

6113 S. J. Bauer, MS 0706

106113 B. L. Ehgartner, MS 0706

6113 T. E. Hinkebein, MS 0706
6113 M. A. Molecke, MS 0706

6113 J. T. Neal, MS 0706

6113 R. W. Ostensen, MS 0706

6113 J. L. Todd, MS 0706

6117 W. R. Wawersik, MS 0751

106117 D. S. Preece, MS 0751

6117 D. H. Zeuch, MS 0751

6121 J. R. Tillerson, MS 1322

513414 Technical Library, MS 0899

12615 Print Media., MS 0619

2 7613-2 Document Processing (for DOE/OSTI), MS 0100

8523-2 Central Technical Files, MS 9018 